\title{
Multiaxial fatigue analysis of notched components using combined critical plane and critical distance approach
}

\author{
Ding Liao a, Shun-Peng Zhu ${ }^{\mathrm{a}, \mathrm{b}, \mathrm{c}, *}$, Guian Qian ${ }^{\mathrm{b}}$ \\ a School of Mechanical and Electrical Engineering, University of Electronic Science and Technology of China, Chengdu 611731, China \\ ${ }^{\mathrm{b}}$ State Key Laboratory of Nonlinear Mechanics (LNM), Institute of Mechanics, Chinese Academy of Sciences, Beijing 100190, China \\ ${ }^{\mathrm{c}}$ Center for System Reliability \& Safety, University of Electronic Science and Technology of China, Chengdu 611731, China
}

\section{A R T I C L E I N F O}

\section{Keywords:}

Critical plane approach

Theory of critical distance

Notch

Multiaxial fatigue

Life prediction

\begin{abstract}
A B S T R A C T
Combinations of geometric discontinuities and multiaxial loads appear commonly in engineering components, which raise both stress gradient and multiaxial stress states near the notch root. This work studies the combined critical plane approach with the theory of critical distance for fatigue analysis of notched components under multiaxial loadings. Taking the Fatemi-Socie model for instance, different coupling sequence of critical plane and critical distance concepts is discussed. In particular, the influence of employing the point method and the line method of the theory of critical distance on predicting performance as well as the rationality of regarding the critical distance as a material constant or as a function related to fatigue life are also investigated. Accordingly, 8 life assessment procedures are summarized and the optimal procedure is determined and verified by experimental data of Al 7050-T7451 and GH4169 alloys. Results show that the majority of the predicted points fall within the \pm 2 scatter band according to experimental results and the procedures which employ the theory of critical distance after using the critical plane approach and regarding the critical distance as a function related to fatigue life provide better accuracy on fatigue life prediction than others.
\end{abstract}

\section{Introduction}

Fatigue is one of the most common failure modes for engineering components. During fatigue design of these components, geometric discontinuities, such as grooves, keys, holes, joints as well as other irregular structures, widely exist to meet various functional requirements. These structures are normally called notches during fatigue analysis. The existence of notch often leads to local stress concentration at the notch root region [1-4]. Even under uniaxial loadings, a complex multiaxial stress field appears near the notch root region; if subjected to multiaxial loadings, the real stress-strain state will be much more complicated, and fatigue cracks are prone to initiate and propagate within these regions [5-8]. According to this, fatigue failure of the whole structure may occur even without any warning of noticeable plastic deformation. In addition, the combination of multiaxial loads and complex geometric structures is inevitable in engineering practice, especially in critical components such as aero engine turbine components with complex transmission structures. In general, the optimal design of notched locations is vital for improving the overall performance of engineering components [9-11].

In order to prevent the catastrophic failure of notched parts and improve its operational safety and reliability in reality, it's essential to study the fatigue mechanism of notched parts under multiaxial loading conditions [12-14]. In this regard, various methods have been developed and/or extended for multiaxial notch fatigue analysis. Among them, some scholars attempted to apply multiaxial fatigue criterion raised to multiaxial notch fatigue analysis directly [2,15-19]. However, these approaches ignored the influence of notch effect on fatigue life, thus generally yield conservative estimations. Considering the accurate analysis of local stress-strain state is critical for fatigue damage evaluation, some researchers focused on calculation of stress-strain at the notch root using either analytical or numerical methods. On the basis of the incremental deviatoric version of the Neuber rule, Ince et al. $[20,21]$ introduced an analytical approximate model which achieves accurate estimation of local elasto-plastic notch stress-strain from pseudo elastic stresses. Through coupling the material constitutive relations with a critical plane-based damage parameter, the analytical modeling approach has been presented for fatigue life assessment of notched components under multiaxial loadings $[22,23]$. On the basis of a new pseudo stress correction method, Tao et al. [24,25] presented a method for local stress-strain computation. Particularly, by coupling with the Kanazawa model, a fatigue life prediction model is established which describes the non-proportional additional hardening effect well. Besides, combing with the Wang-Brown cycle count process, Tao [25] extended the

\footnotetext{
* Corresponding author at: School of Mechanical and Electrical Engineering, University of Electronic Science and Technology of China, Chengdu 611731, China. E-mail address: zspeng2007@uestc.edu.cn (S.-P. Zhu).
} 


\section{Nomenclature}

Symbols

A Model relevant parameter of the TCD

$B \quad$ Model relevant parameter of the TCD

$b_{0} \quad$ Shear fatigue strength exponent

$c_{0} \quad$ Shear fatigue ductility exponent

E Elastic Modulus

$F_{a, t} \quad$ Applied normal axial force amplitude

$f \quad$ Load frequency

$G \quad$ Shear modulus

$K^{\prime} \quad$ Cyclic strength coefficient

$K_{t} \quad$ Stress concentration factor

$\Delta K_{t h} \quad$ Amplitude of the threshold value of the stress intensity

factor

$k \quad$ Fatemi-Socie parameter

$L \quad$ Critical distance

$N_{f} \quad$ Number of cycles to failure

$n^{\prime} \quad$ Cyclic strain hardening exponent

$S_{F, a, t} \quad$ Applied normal axial stress amplitude

$S_{T, a, t} \quad$ Applied shear stress amplitude

$T \quad$ Test temperature

$T_{a, t} \quad$ Applied shear force amplitude

$v_{e} \quad$ Elastic Poisson's ratio

$v_{p} \quad$ Plastic Poisson's ratio

$\phi \quad$ Load phase angle

$\varepsilon_{a, t} \quad$ Applied normal axial strain amplitude

$\bar{\varepsilon}_{a, t} \quad$ Applied equivalent strain amplitude

$\sigma_{b} \quad$ Tensile strength

$\sigma_{n, \max } \quad$ Maximum normal stress on the critical plane

$\sigma_{o} \quad$ Plain fatigue limit

$\Delta \sigma_{o} \quad$ Range of the plain fatigue limit

$\sigma_{0.2} \quad 0.2 \%$ offset yield stress

$\sigma_{y} \quad$ Cyclic yield stress

$\tau_{f}^{\prime} \quad$ Shear fatigue strength coefficient

$\gamma_{a} \quad$ Maximum shear strain amplitude on the critical plane

$\gamma_{a, t} \quad$ Applied shear strain amplitude

$\gamma_{f}^{\prime} \quad$ Shear fatigue ductility coefficient

AM area method of the TCD

CPA critical plane approach

FEA finite element analysis

FS Fatemi-Socie

HCF high cycle fatigue

LCF low cycle fatigue

LM line method of the TCD

PM point method of the TCD

SWT Smith-Watson-Topper

TCD theory of critical distance

VM volume method of the TCD

computational methodology to fatigue life prediction of notched component subjected to variable amplitude multiaxial loadings.

Moreover, considering the exclusive advantage of critical plane approaches (CPA) in multiaxial fatigue analysis as well as application of the theory of critical distance (TCD) in notch effect analysis, some researchers attempted to couple them for multiaxial notch fatigue assessment. Through regarding the maximum shear stress plane as the critical plane, Susmel et al. [26] integrated the point method in the TCD and Whöler curve method for fatigue life prediction. Following the idea of local stress-strain method, $\mathrm{Wu}$ [27] initially assessed the fatigue strength of notch components by employing a new multiaxial fatigue damage model with stress-strain data extracted from the notch roots. However, he ignored the influence of notch effect, thus the prediction results were overall conservative with certain scatter bands. To effectively character- ize the influence of damage gradient on fatigue strength, the TCD is normally introduced for model correction, and methods for determining the fatigue critical distance of the notched parts under multiaxial loads have been presented based on point method and line method respectively. Liu et al. [28] combined the CPA and the TCD directly, regarding the plane with maximum shear stress range as the critical plane, and the mean value of the maximum effective shear stress and the maximum effective normal stress in the halfsphere volume centers at the peak stress point as the damage parameter, where a good agreement was indicated. Gates et al. $[1,29,30]$ firstly performed the stress-strain analysis of notched parts based on pseudo stress plastic modeling method, and then fatigue lives of notch specimens made of Al 2024-T3 alloys were predicted by combining the modified Fatemi-Socie (FS) model with the TCD. Though nearly all prediction points fall within \pm 3 time scatter band, the accuracy and robustness of their procedure under multiaxial loadings still have great potentials for further improvement. Thus, the combination of critical distance/plane method is definitely promising.

In addition to the abovementioned models, for multiaxial notch fatigue assessment, Berto et al. [31-35] utilized the mean value of local strain energy density (SED) near the notch tip in the controlled volume as the damage parameter for fatigue analysis. Ye et al. [36] established an approximate energy conversion relationship for life assessment based on thermodynamic analysis of cyclic plastic deformation. Meggiolaro et al. [37] developed a "unified notch rule" for notch fatigue assessment, which considers the influence of non-zero normal stresses perpendicular to the free-surface on fatigue life. Liu et al. [38] proposed a method which employs the modified multiaxial crossland fatigue criterion to enable fatigue modeling under non-proportional stress states with varying principal directions and the cycle jumping algorithm to increase the efficiency of fatigue damage accumulation with the presence of evolution of plasticity. Moreover, except for crack nucleation process, crack growth also influences the total fatigue life. Hassanifard et al. [39,40] investigated the fatigue crack propagation progress based on employing stress intensity factors and microstructural parameters respectively, both of them yield reasonable correlations with experimental data.

Recently, Luo et al. [41] combined the CPA and the TCD for fatigue life assessment of thin-walled notch specimens with circular hole. In this case, accurately determining the position of the dangerous point is the key step of the analysis. By employing the analytic method, they indicated that the point on the edge of the center hole always present a uniaxial stress state, and the direction of the principal stress is tangent to the notch edge curve. On this basis, the point on the notch edge which experiences the maximal stress in the stable load cycle is regarded as the critical point. Afterwards, they simplified the thin-walled structure into a shell element in FEA. By drawing a circle of radius $L$ about the critical point and then connect the points on the circle to the critical point, a series of planes can be obtained (all of the planes are perpendicular to the plane where the circle is located). Among them, the plane with the maximum shear stress amplitude is defined as the critical plane, and the TCD is applied along the radial direction passes through this plane. By introducing experimental data of GH4169, LY12CZ and TC4 alloys for model verification, the maximum error between the predicted angle of critical plane and the tested one is only $9.6^{\circ}$, which predicts the crack initiation positions and their expansion directions accurately, thus provides a reference for the subsequent research in fatigue fracture analysis. However, dispersion between the predicted lives and test results still exists, and the transformation from the two-dimensional shell structures to the multiaxial fatigue analysis of three-dimensional notched structures needs to be further explored. To conclude, the solution to multiaxial notch fatigue analysis is still lacking, more efficient solutions are highly expected.

In this paper, taking the FS model as the start point, different coupling sequence of the CPA with the TCD for fatigue analysis of notched components under multiaxial loadings is systemically studied. In addition, the relationship between critical distance and fatigue life is also investigated. Accordingly, 8 life assessment procedures are summarized 


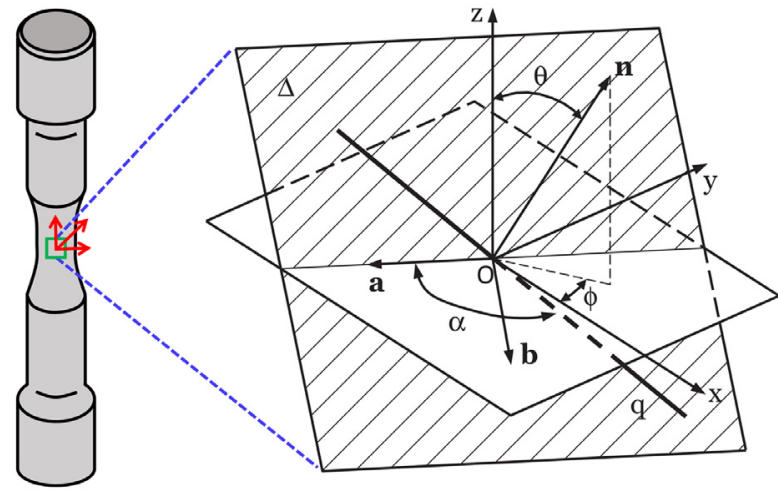

Fig. 1. Schematic diagram for determining the critical plane under multiaxial loadings.

and the optimal procedure is determined and verified by experimental evidence. The rest of this article is structured as follows: In Section 2, a brief review on the CPA and the TCD is given as the theoretical background. Section 3 discusses and verifies the optimal coupling sequence of critical plane-distance approaches by experimental data of $\mathrm{Al} \mathrm{7050-}$ T7451 notched specimens as well as that of GH4169 alloys. Finally, Section 4 draws the conclusions.

\section{Theoretical background}

\subsection{Critical plane approach (CPA)}

Recently, increasing attentions have been paid on the study of multiaxial fatigue $[42,43]$. Among them, critical plane approaches are the mainstream of research [44-48], which connects theory with the physical observation of fatigue cracking behavior. Specifically, the concepts of critical planes are established based on fatigue cracking mechanism with certain physical significance, thus are more effective for multiaxial fatigue assessment. Fatigue life analysis based on the CPA mainly consists of two steps: the first step is to determine the critical plane according to different loading conditions, then develop the multiaxial fatigue damage parameter based on the history of stress and strain on the critical plane, and further predict fatigue life of interest. For the critical plane, researchers have come up with different definitions [49]. To sum up, for high cycle fatigue (HCF) analysis, the critical plane can be chosen as the maximum shear stress plane, the maximum principle stress plane or the plane of the maximum damage parameter; while for low cycle fatigue (LCF) analysis, options for the critical plane include the maximum shear strain plane, maximum normal strain plane as well as the plane of the maximum damage parameter [46]. Fig. 1 depicts the process for determining the critical plane.

The key step of critical plane-based approaches is the determination of the critical plane. Wang et al. [50] introduced the mathematical formalization in coordinate transformation, and elaborated the searching procedure of the critical plane. Herein, a brief introduction on fatigue strength assessment by employing the critical plane approach is attached as follows:

(1) Through the load spectrum analysis under actual operating mode, perform elasto-plastic finite element analysis (FEA) of the interest.

(2) Determine the dangerous regions according to the stress and strain distribution, and extract the 12 stress-strain components of the elements (or nodes) within the dangerous regions with stabilized loading cycles.

(3) Search the critical plane corresponding to the selected CPA by converting the coordinate system. The search of critical plane is achieved by angular scanning of three unit vectors $a, b$ and $n$ at the internal reference point $O$. To be specific, this procedure can be realized by changing the directions $\varphi$ and $\theta$ with $5^{\circ}$ increments in Matlab program, where $0 \leq \varphi \leq 360^{\circ}, 0 \leq \theta \leq 180^{\circ}$.

(4) Through performing coordinate transformation, constituent elements of the damage parameter corresponding to the critical plane approach can also be determined, thus the predicted lifetime can be obtained by substituting the damage parameter into the multiaxial fatigue model.

Note that the applicability of the CPA is closely related to the fatigue damage mechanism. More precisely, there are three cracking modes, namely tensile failure mode (Mode I), shear failure mode of in-plane shear loading (Mode II) as well as shear failure mode of out-of-plane shear loading (Mode III) [49]. Correspondingly, the algorithms for fatigue life evaluation based on the CPA are specified linked to the dominating crack type, and the dominant parameters as well as the critical plane orientations in each failure mode are fundamentally different [51]. Therefore, pre-evaluating the failure dominant mode and selecting an appropriate critical plane model is a vital step to improve the prediction accuracy.

Yu et al. [52,53] summarized models developed on the basis of the critical plane. Note from recent models proposed by $\mathrm{Wu}$ [54] and $\mathrm{Yu}$ [46] that accurate life assessment under complex multiaxial proportional/non-proportional loadings can be achieved by considering the influence of the non-zero mean stress, which provides theoretical support for structural integrity assessment of components under complex loadings. Besides, Karolczuk et al. [51] reviewed the historical development of critical plane approaches and systematically classified the critical plane models by damage parameters of stress, strain or strain energy. Moreover, the adaptive failure dominant mode and the applicability under various types of loads of each method are also attached, which provides a reference for accurate selection of critical plane approaches.

Herein, as one of the most commonly used critical plane approach in practice, the Fatemi-Socie (FS) model [55] is chosen for feasibility verification on the combination of the critical plane-critical distance approaches. Specifically, FS criterion was developed on the basis of the model raised by Brown and Miller [56]. Considering the friction caused by uneven crack surfaces, which decreases the stress at the crack tip, thus retards crack growth and extends its fatigue life span; besides, the tensile stress disjoints the crack surface and diminishes the friction, and then speeds up the crack propagation process, they substituted the normal strain by the normal stress term as:

$\gamma_{a}\left(1+k \frac{\sigma_{n, \max }}{\sigma_{y}}\right)=\frac{\tau_{f}^{\prime}}{G}\left(2 N_{f}\right)^{b_{0}}+\gamma_{f}^{\prime}\left(2 N_{f}\right)^{c_{0}}$

where $\gamma_{a}$ is the maximal shear strain amplitude, $k$ is a material constant which depicts the impact of normal stress on fatigue damage, $\sigma_{n, \max }$ is the peak normal stress on the critical plane, occurring at any moment during the stabilized loading cycle, $\sigma_{y}$ is the yield strength, $G$ is the shear modulus, $\tau_{f}^{\prime}, \gamma_{f}^{\prime}, b_{0}$ and $c_{0}$ are the shear fatigue parameters. It's worth mentioning that the FS criterion can characterize the influence of additional cyclic hardening on fatigue damage under out-of-phase loading resulting from the rotation of principal axes. Besides, another critical plane approach proposed by Smith, Watson and Topper [57] (hereinafter referred to the SWT model) is also employed for screening test points, which will be elaborated in the next section.

\subsection{Theory of critical distance}

In virtue of the serviceability for structures with complex features and the convenience in practice, the theory of critical distance (TCD) has been adopted for notch fatigue analysis [58,59]. Assuming that the elastic stress near the notch root does not attain those values figured employing the theory of continuum mechanics, to obtain an engineering quantity representing the effective stress damaging the fatigue process zone, Neuber $[60,61]$ averaged the elastic stress over a critical 


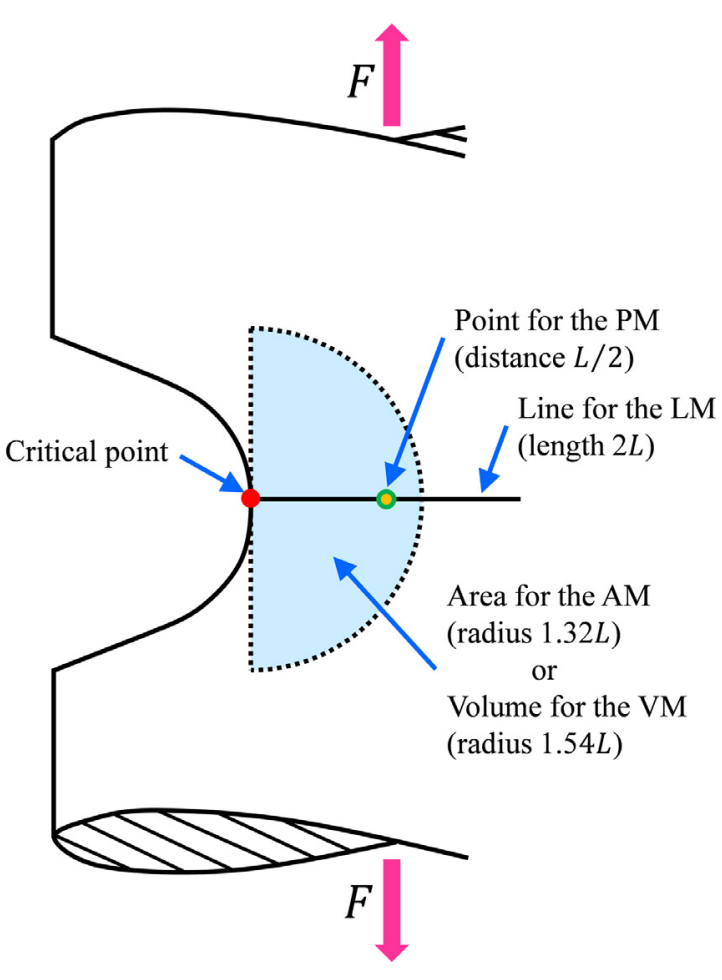

Fig. 2. Schematic diagram of the TCD method for PM, LM, AM and VM.

distance from the notch root, which was named as the line method (LM). Later, Peterson [62] pointed out that the reference stress employed to compare with the material fatigue limit of smooth specimens for life prediction can be simplified as the stress value at a given length from the notch tip, which is named as the point method (PM). Afterwards, Taylor [63] reperformed the same idea in a different way by averaging the stresses over semicircular area near the notch root, namely the area method (AM). Recently, Bellett et al. [64] made use of a volume average and extended the concept to a halfsphere centered at the notch tip, which is named as the volume method (VM). The abovementioned four categories of TCD methods are illustrated schematically in Fig. 2.

The equations of TCD are:

PM : $\quad \sigma(L / 2)=\sigma_{o}$

$\mathrm{LM}: \quad \frac{1}{2 L} \int_{0}^{2 L} \sigma(r) d r=\sigma_{o}$

$\mathrm{AM}: \quad \frac{2}{\pi(1.32 L)^{2}} \int_{-\frac{\pi}{2}}^{\frac{\pi}{2}} \int_{0}^{1.32 L} \sigma(r, \theta) r d r d \theta=\sigma_{o}$

$\mathrm{VM}: \quad \frac{3}{2 \pi(1.54 L)^{3}} \int_{0}^{\pi} \int_{-\frac{\pi}{2}}^{\frac{\pi}{2}} \int_{0}^{1.54 L} \sigma(r, \theta, \varphi) r^{2} \sin \theta d r d \theta d \varphi=\sigma_{o}$

Among them, the PM considers that fatigue failure occurs when the stress at the point at a certain distance from the tip (surface/exterior) of the notch reaches the fatigue limit $\sigma_{o}$ of smooth specimens [65]. Analogously, the LM, AM and VM share the failure judgement/criterion, except for different strategies to extract effective stress. In summary, during fatigue strength assessment of notched parts/specimens, the TCD bypasses the regions with the maximum stress level at the notch tip while employing the point of relatively low stress level or average stress over a given line/area/volume as judgement, thus enables the predicted results are closer to the real fatigue lives.

Normally, the critical distance $L$ can be obtained by [65]:

$L=\frac{1}{\pi}\left(\frac{\Delta K_{t h}}{\Delta \sigma_{o}}\right)^{2}$ where $\Delta K_{t h}$ and $\Delta \sigma_{o}$ are the range of the threshold stress intensity factor and the plain fatigue limit, respectively. In particular, the critical distance is closely related to the grain size and the ability to retard crack propagation of the material of interest. However, during lifetime estimation of notched components in the medium-cycle fatigue regime, Susmel and Taylor [66] regarded the critical distance as a fatigue life related function, which decreases with the fatigue life; while in their subsequent research to assess fatigue lives of notched parts in the scope of low/medium-cycle fatigue, the critical distance is assumed as material constant whose value relates to neither notch geometry nor to the number of cycles to failure [67], which can be expressed as follow:

$L=A N_{f}^{B}$

where $A$ and $B$ are model relevant parameters.

In engineering practice, as the load level rises, the volume of the plastic zone near the notch also increases, thus a larger fatigue process zone appears, which is in accordance to Eq. (7) as above mentioned. On the basis of the research of Susmel and Taylor, considering the impact of the severity of stress concentration on the critical distance, Yang et al. [68] and Huang et al. [69] successively modified the expression between the fatigue life and the critical distance by coupling stress concentration factor $K_{t}$ (as presented in Eqs. (8) and (9)), which correlates well with tested lives.

$K_{t} * L=A N_{f}^{B}$

$K_{t}^{m} * L=A N_{f}^{B}$

where $m$ is a model relevant parameter.

However, regarding the critical distance as a function related to fatigue life implies that the value of critical distance is unknown before analysis, thus a recursive procedure must be included. Besides, using three multiaxial fatigue criteria, Castroa et al. [70] studied the HCF behaviors of four kinds of steel combining the TCD; results show that the value of critical distance is closely linked to the selected fatigue criterion, which challenges the universality of TCD. Accordingly, in this work, an optimal method for determining the value of critical distance in the combined analysis of CPA-TCD is also included.

\section{Combined critical plane-critical distance approaches for multiaxial fatigue analysis}

\subsection{Recent progress on coupled CPA-TCD analysis}

As engineering components operates, impact of multiaxial fatigue and notch effects on fatigue damage generally exist jointly, as depicted in Fig. 3 (in which the data points are extracted form elasto-plastic FEA results of Al 7050-T7451 notched specimen NA1, its geometry, dimensions, and load spectrum are given in Fig. 6(a) and Table 2, respectively). Specifically, the distribution of elasto-plastic stress/strain near the notch root are extracted by using the FE software ANSYS 17.0 with 20-node quadratic brick 3D elements Solid 186.

Fig. 3 depicts the inhomogeneous stress distribution along the radial direction. Based on two assumptions: (a) the critical distance is a material relevant constant which can be obtained from symmetric uniaxial fatigue testing, (b) damage parameters in multiaxial fatigue criteria can characterize the effects of non-zero mean stress and non-zero non-proportional loading, Taylor and Susmel [71] studied the feasibility of coupling analysis between several multiaxial fatigue criteria and the TCD. By introducing vast amount of data from multiaxial notch fatigue tests for model verification, they found that the critical plane approaches are the only multiaxial fatigue criteria which can coherently be re-interpreted in terms of the TCD. Susmel [58] summarized the application of TCD in fatigue analysis in recent years, and pointed out that it is a practical and effective method for notch fatigue analysis, but its potential in fatigue life evaluation of notched parts under complex multiaxial loads still remains to be investigated. Besides, Castro [70] indicated 
(a)

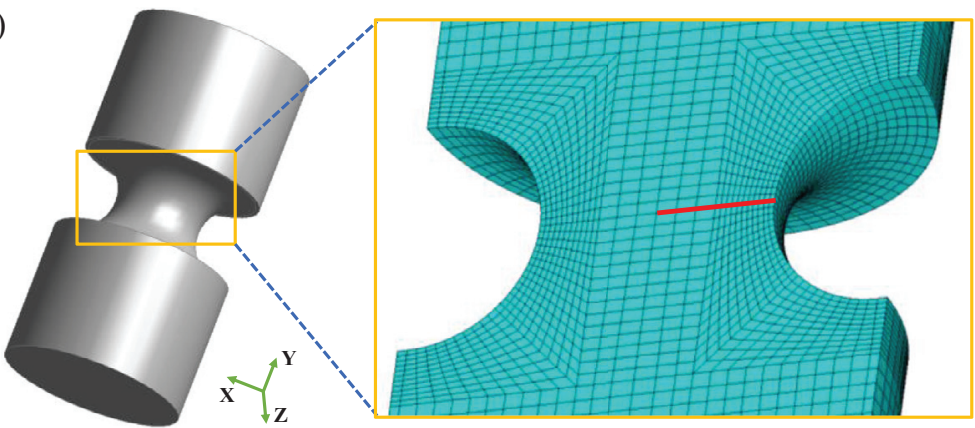

(b)

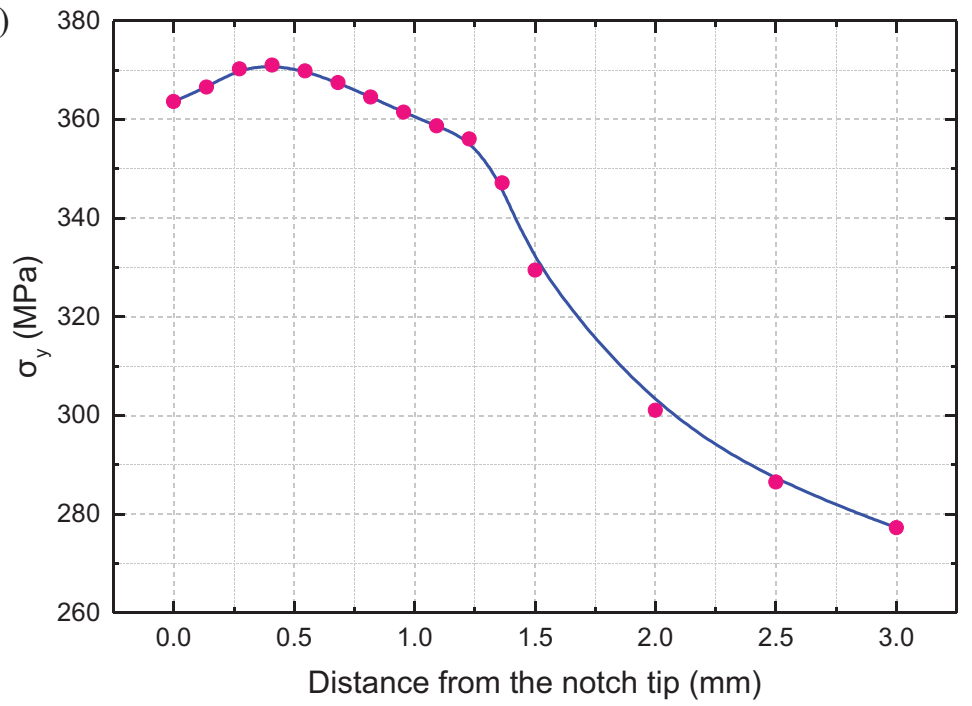

Fig. 3. Stress distribution along the radial direction on the minimum cross section of notched specimen NA1: (a) path diagram (red line), (b) stress distribution of $\sigma_{y}$ component.(For interpretation of the references to colour in this figure legend, the reader is referred to the web version of this article.) that the coupling analysis of critical plane-critical distance approaches is worthy to be attempted, but the premise is that the combination should be consistent with the mechanism of multiaxial fatigue failure.

Based on a new material constitutive model, Leidermark et al. [72] analyzed the fatigue crack processing behaviors of notched specimens with single crystal superalloy MD2 by combining the CPA and the TCD. Specifically, the maximum total shear strain range on the crystallographic slip systems was employed to locate the critical slip coordinate, and then the damage parameters are obtained by applying the TCD along the critical plane. Finally, the fatigue life is calculated by Manson-Coffin equation. In addition, they also explored the rationality that regarding the critical distance as a constant or a function related to fatigue lifetime, and results show that the second strategy yields better corrections than others. Moreover, Akama [73] linked the TCD with the CPA developed by Jiang and Sehitoglu [74] and applied them to the rolling contact analysis of railway wheels and rails; regarding the potential starting slip system in face-centered cubic crystal structure as the critical plane and the maximum resolved shear strain range $\Delta \gamma_{\max }$ as the damage parameter, Huang et al. [69] evaluated the fatigue life of DZ125 notched examples under LCF by coupling the CPA and the TCD, which improves the prediction accuracy to within the two-time scatter band.

\subsection{Strategies for coupled CPA-TCD analysis}

Combining with the previous discussion and introduction, this work studied the following three items:

(1) Exploring the influence of the coupling sequence of the CPA and the TCD on the life prediction. As shown in Fig. 4, there are two strategies for multiaxial fatigue analysis using combined critical plane-
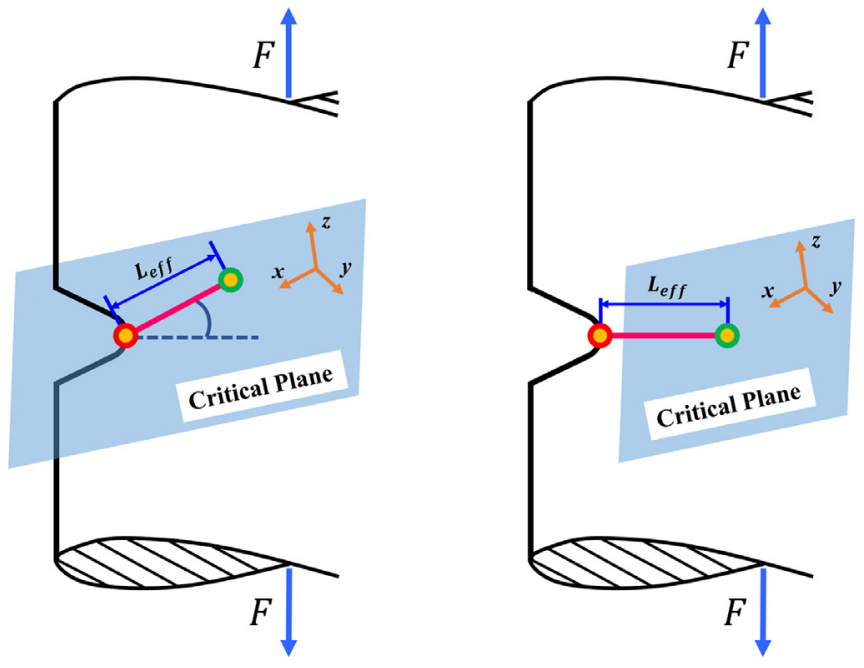

Fig. 4. Schematic diagram of two strategies for combined critical plane-critical distance approaches analysis

(a) Sequence 1 (CPA $\rightarrow$ TCD), (b) Sequence 2 (TCD $\rightarrow$ CPA).

critical distance approaches. Note from the subgraph Fig. 4(a), the first plan employs the CPA before the TCD. Firstly, extract the stress and strain components at the critical point; then, search and determine the critical plane according to its definition in the corresponding critical plane model; finally, apply the TCD on the critical plane to predict the fatigue life. While the second plan uses the TCD firstly, as illustrated in subgraph Fig. 4(b). Along the radial direction of the 


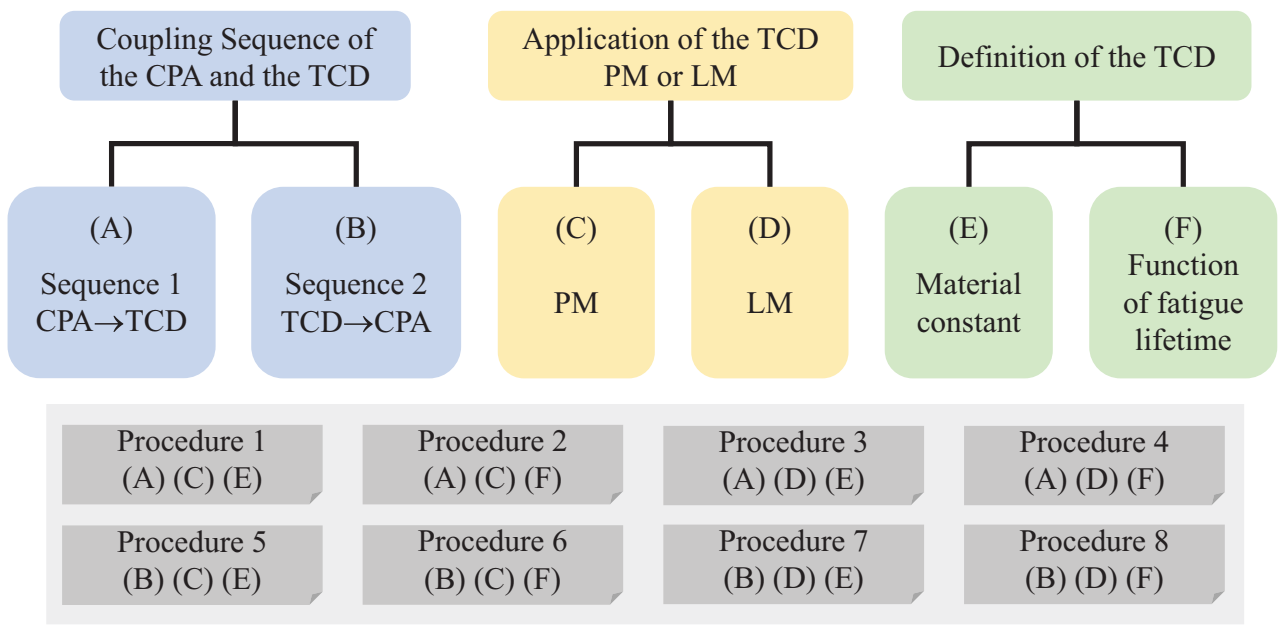

Fig. 5. Eight procedures for life assessment.

Table 1

Material properties of Al 7050-T7451 and GH4169 alloys [16,25].

\begin{tabular}{lllllllll}
\hline Material & $T\left({ }^{\circ} \mathrm{C}\right)$ & $E(\mathrm{GPa})$ & $\sigma_{0.2}(\mathrm{MPa})$ & $\sigma_{b}(\mathrm{MPa})$ & $v_{e}$ & $v_{p}$ & $K^{\prime}(\mathrm{MPa})$ & $n^{\prime}$ \\
\hline Al 7050-T7451 & 25 & 70.3 & 455 & 510 & 0.33 & 0.5 & 734.5139 & 0.09697 \\
$\mathrm{GH} 4169$ & 650 & 182 & 1000 & 1150 & 0.325 & 0.5 & 1950 & 0.15 \\
\hline
\end{tabular}

bisecting plane of the specimen, the TCD is primarily applied starting from the critical point; then, employing the CPA and thus the predicted fatigue lifetime can be obtained.

(2) Discuss the influence on the precision of fatigue life prediction when employing point method (PM) and line method (LM) of the TCD, respectively.

(3) Investigate the rationality of regarding the critical distance $L$ as a material constant or as a fatigue life related function during life prediction.

As illustrated in Fig. 5, through the free combination of the above three research items, 8 life assessment procedures can be summarized. For instance, in Procedure 1, the CPA is employed in the critical point to determine the location of the critical plane firstly. Next, the TCD is applied on the critical plane. Specifically, the point method is chosen and the critical distance is regarded as a material distance. By coupling FE analysis and experimental results, the critical distance of each specimen can be determined. Then, collecting critical distances of all specimens, the law of critical distance can be established, which will be elaborated in Section 3.3.2. Finally, the predicted lives of notched specimens can be calculated. In the subsequent contents, the feasibility of the abovementioned options will be verified and their predicting performances will be compared and discussed. Specially, the FS model mentioned in Section 2.1 is utilized for model verification of the combination of the critical plane-critical distance approaches, which can characterize the influence of additional cyclic hardening effect on fatigue damage under out-of-phase loading resulted from the rotation of principal axes.

\subsection{Feasibility verification and comparison}

\subsubsection{Materials and experiments}

Experimental data of notched specimens of aluminum alloy Al 7050T7451 [25] and nickel-based alloy GH4169 [16] are utilized for model validation, and their mechanical properties are tabulated in Table 1. Fig. 6 presents geometries and dimensions of grooved shaft specimens. Tables 2-4 list corresponding multiaxial load conditions as well as tested lives of each specimen, and the load ratio (including $R_{\sigma}$ and $R_{\varepsilon}$ ) are both -1 . Specially, tests of Al 7050-T7451 specimens were carried out under Sine load waveform while GH4169 specimens under strain-controlled
Table 2

Fatigue test results of $\mathrm{Al}$ 7050-T7451 notched specimens under strain control mode [25].

\begin{tabular}{lllllll}
\hline No. & $\phi\left(^{\circ}\right)$ & $\bar{\varepsilon}_{a, t}(\%)$ & $\varepsilon_{a, t}(\%)$ & $\gamma_{a, t}(\%)$ & $f(\mathrm{~Hz})$ & $N_{f}$ (Cycles) \\
\hline NA1 & 0 & 0.3 & 0.2121 & 0.3674 & 1 & 1217 \\
NA2 & 0 & 0.25 & 0.1768 & 0.3062 & 1 & 2282 \\
NA3 & 0 & 0.2 & 0.1414 & 0.2449 & 1 & 3831 \\
NA4 & 0 & 0.18 & 0.1277 & 0.2211 & 1 & 16,034 \\
NA5 & 0 & 0.15 & 0.11 & 0.19 & 1 & 48,671 \\
NA6 & 45 & 0.2 & 0.1531 & 0.2651 & 1 & 2580 \\
NA7 & 90 & 0.2 & 0.2 & 0.3464 & 1 & 1071 \\
\hline
\end{tabular}

constant amplitude loading with a triangle wave. Moreover, an extensometer with a gage length of $25 \mathrm{~mm}$ is set up for Al 7050-T7451 specimens and gage length $50 \mathrm{~mm}$ for GH4169 specimens. Material properties and heat treatment of GH4169 alloys can be found in [75-77]. In particular, for Al 7050-T7451 specimens, they were manufactured from hot rolled aluminum alloy bars of $30 \mathrm{~mm}$ in diameter. Firstly, a solution treatment process was performed. Then, by applying a certain level tensile load, the residual stress was relieved. Next, an artificial overaging process was employed to obtain the material's best resistance to stress corrosion. Finally, manufactured aluminum alloy bars into grooved shaft specimens according to the technological requirements. For GH4169 specimens, the specimens were machined from bars with a diameter of $25 \mathrm{~mm}$. Before machining bars into specimens, a standard heat treatment process is performed as follows: $970^{\circ} \mathrm{C}$ for $1 \mathrm{~h}$ and then air cooling to $720^{\circ} \mathrm{C}$ for $8 \mathrm{~h}$, furnace cooling with rate of $50^{\circ} \mathrm{C} / \mathrm{h}$ to $620^{\circ} \mathrm{C}$ for $8 \mathrm{~h}$ and finally air cooling.

In order to evaluate the predicting performances of each procedure mentioned above more reasonably, multiaxial fatigue test data of $\mathrm{Al}$ 7050-T7451 notched examples with larger data base are employed. Before verification, a screening procedure for test points is performed. Firstly, FE simulation of each notched specimen is carried out according to the test load spectrum, thus the stress and strain data of the critical point in the notch tip are obtained; afterwards, by using the FS model [55] and the SWT model [57], fatigue life of each specimen can be then evaluated. The relation between tested lives and predicted lives for $\mathrm{Al}$ 7050-T7451 notched specimens are shown in Fig. 7. 
(a)

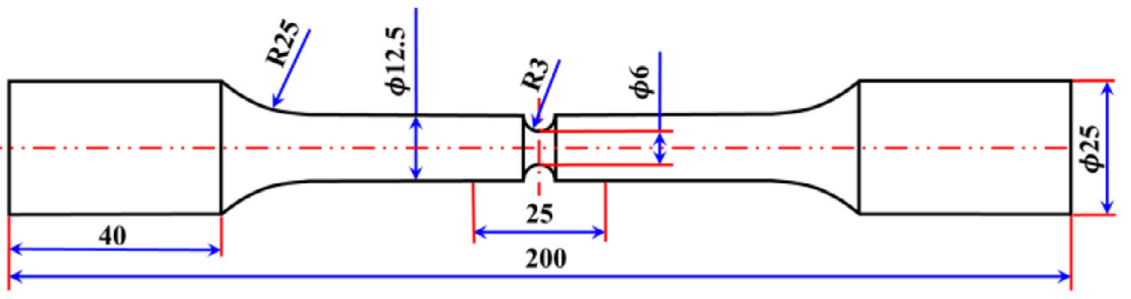

(b)

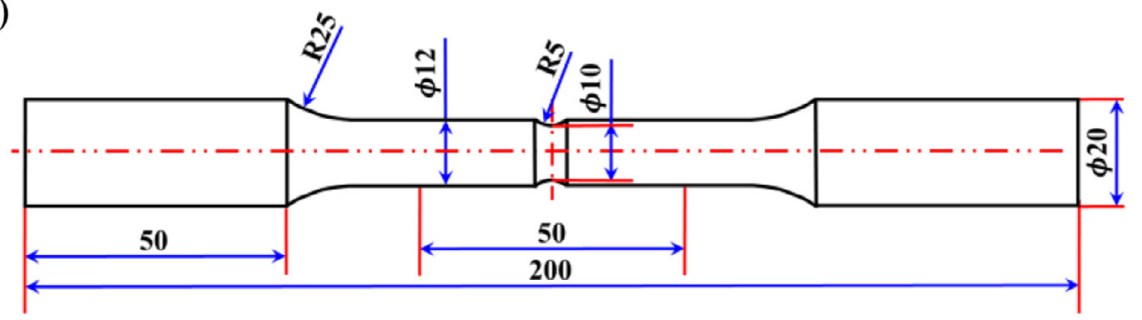

Fig. 6. Specimen geometries and dimensions for (a) Al 7050-T7451 grooved shaft specimen, (b) GH4169 grooved shaft specimen. (All dimensions are in $\mathrm{mm}$ ).

Table 3

Fatigue test results of Al 7050-T7451 notched specimens under load control mode [25].

\begin{tabular}{llllllll}
\hline No. & $\phi(\odot)$ & $F_{a, t}(\mathrm{kN})$ & $T_{a, t}(\mathrm{~N} \bullet \mathrm{m})$ & $S_{F, a, t}(\mathrm{MPa})$ & $S_{T, a, t}(\mathrm{MPa})$ & $f(\mathrm{~Hz})$ & $N_{f}(\mathrm{Cycles})$ \\
\hline NB1 & 0 & 4.6133 & 3.8853 & 162.7082 & 90.9717 & 3 & 85,778 \\
NB2 & 0 & 11.4995 & 9.8061 & 408.0743 & 233.6957 & 3 & 214 \\
NB3 & 0 & 6.9227 & 5.9096 & 244.594 & 141.9901 & 3 & 4447 \\
NB4 & 0 & 9.1983 & 7.8954 & 325.8599 & 187.8325 & 3 & 922 \\
NB5 & 45 & 6.9165 & 5.9055 & 244.5101 & 141.1744 & 3 & 5984 \\
NB6 & 90 & 6.8907 & 5.9276 & 244.5054 & 140.4185 & 3 & 3981 \\
NB7 & 90 & 11.4812 & 9.9487 & 407.4768 & 235.8627 & 3 & 327 \\
NB8 & 90 & 9.2128 & 7.9224 & 326.5792 & 188.233 & 3 & 804 \\
\hline
\end{tabular}

Table 4

Fatigue test results of GH4169 notched specimens [16].

\begin{tabular}{llllll}
\hline No. & $\phi\left({ }^{\circ}\right)$ & $\varepsilon_{a, t}(\%)$ & $\gamma_{a, t}(\%)$ & $f(\mathrm{~Hz})$ & $N_{f}$ (Cycles) \\
\hline NC1 & 0 & 0.00282 & 0.0037 & 0.2 & 1076 \\
NC2 & 0 & 0.00419 & 0.00675 & 0.1 & 139 \\
NC3 & 0 & 0.00281 & 0.00392 & 0.2 & 871 \\
NC4 & 45 & 0.00354 & 0.00479 & 0.2 & 642 \\
NC5 & 45 & 0.00357 & 0.00487 & 0.2 & 509 \\
NC6 & 90 & 0.00397 & 0.0055 & 0.2 & 469 \\
NC7 & 90 & 0.00238 & 0.00306 & 0.2 & 10,053 \\
NC8 & 90 & 0.00395 & 0.00553 & 0.2 & 425 \\
NC9 & 90 & 0.00297 & 0.0041 & 0.2 & 2086 \\
\hline
\end{tabular}

As can be seen from Fig. 7, the FS and the SWT models give conservative life predictions for most of the specimens when applying the stressstrain data at the critical point for fatigue analysis directly; however, there are still three specimens with overestimated life comparing with the tested one, which deviates from the objective facts (which might result from material variation as well as experimental uncertainty). It is well known that due to the notch effect, irregular shaped components with local stress concentration present higher LCF lifetime than that figured by extracting nominal stresses in the carve or notch tip only, for stress levels drop from the surface into the interior of the part thus retard LCF crack formation in the critical grain [78-81]. Moreover, Fig. 8 presents the calculated lifetime distribution of notched specimen NA2 along the direction applying the TCD by employing combined analysis of the critical plane-critical distance approaches with two coupling sequence, respectively. Note from Fig. 8, the points further inside the body own higher fatigue lives than those located near the surface, which means that the TCD can't achieve the correction of the optimistic predicted results obtained by using the CPA. Therefore, several test results

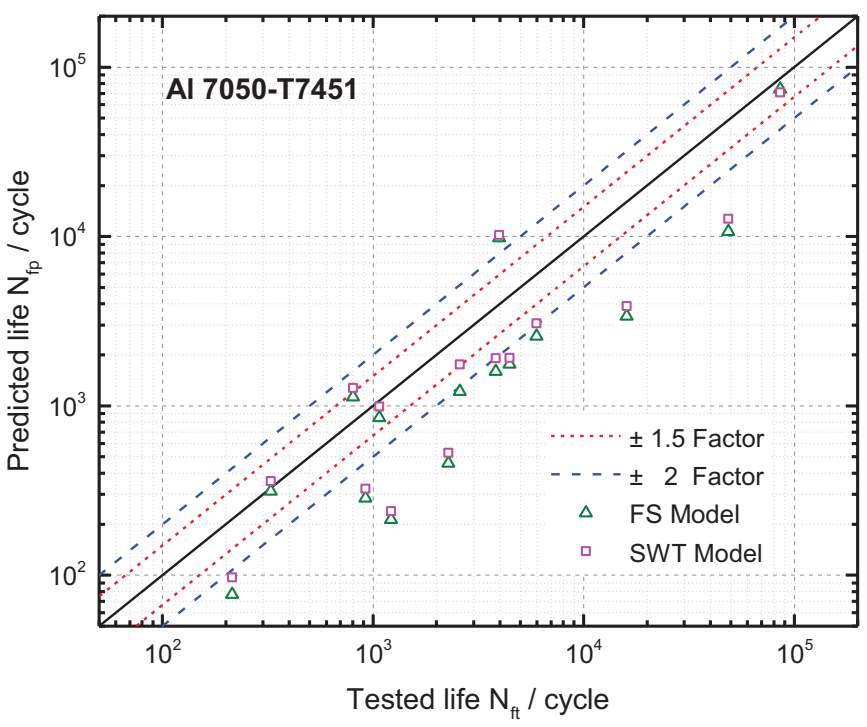

Fig. 7. Comparison between tested and predicted lives of $\mathrm{Al}$ 7050-T7451 notched specimens by using the FS and SWT models.

that do not correspond to objective facts were discarded before the analysis, including the test specimens numbered NB6, NB7, and NB8.

\subsubsection{Validation and comparison}

By combining the CPA and the TCD for fatigue analysis with different coupling sequences (PM and LM in the TCD are employed respectively), relationship diagrams between fatigue lives and critical distances of $\mathrm{Al}$ 7050-T7451 specimens are presented as shown in Figs. 9 and 10, and 


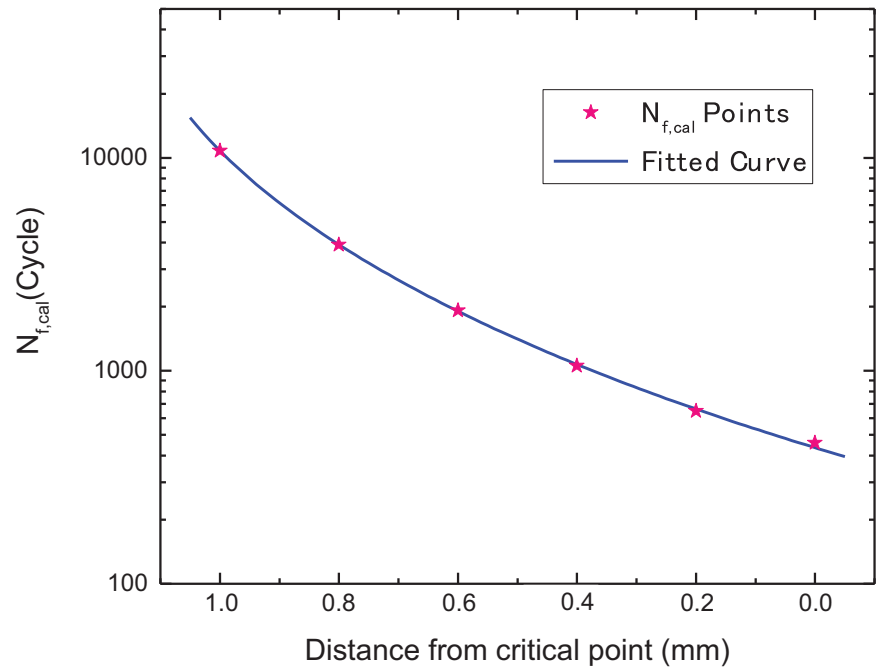

(a)

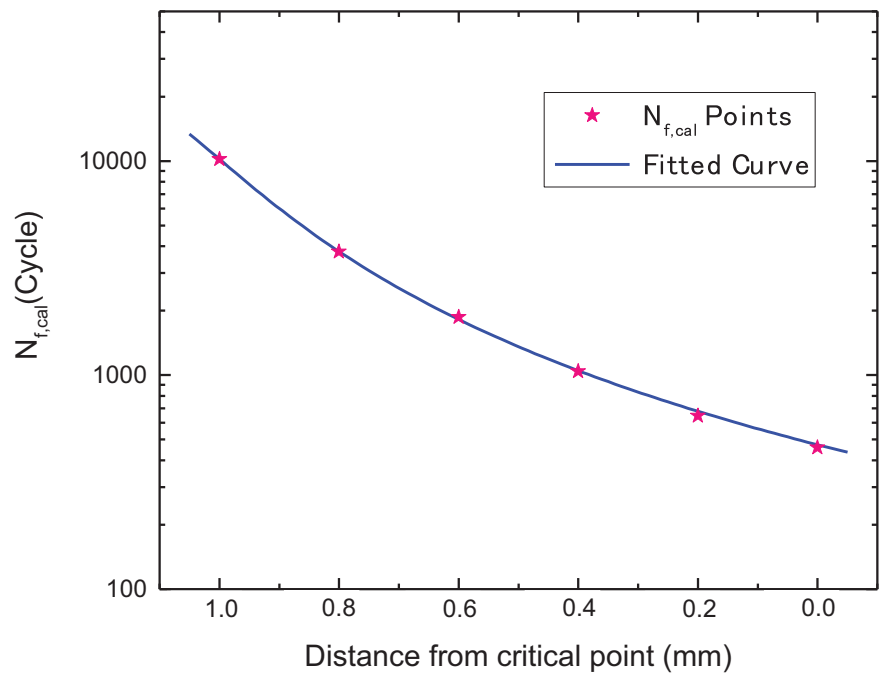

(b)

Fig. 8. Predicted life distribution of notched specimen NA2 along the direction applying the TCD. (a) Sequence 1 (CPA $\rightarrow$ TCD), (b) Sequence 2 (TCD $\rightarrow$ CPA).

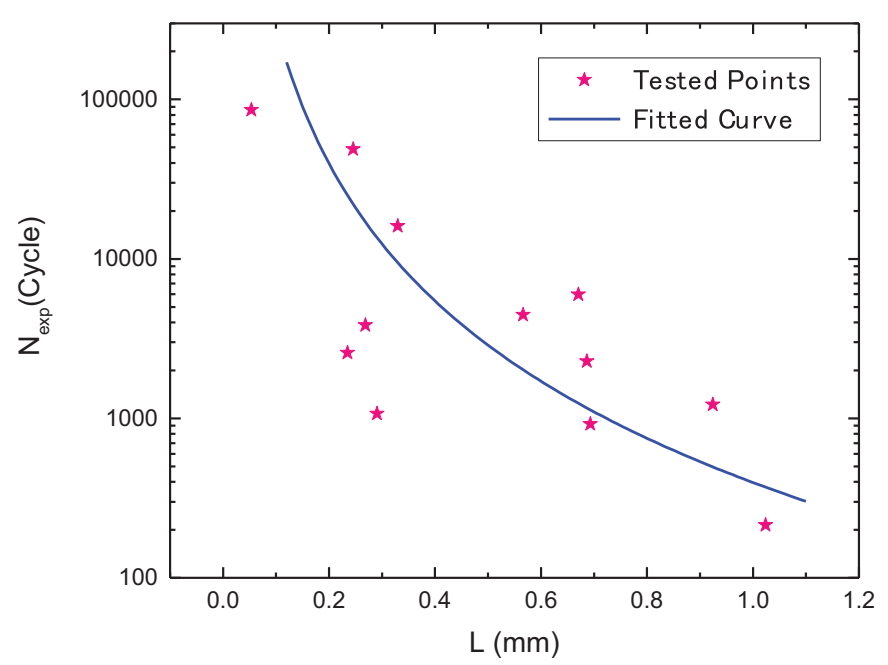

(a)

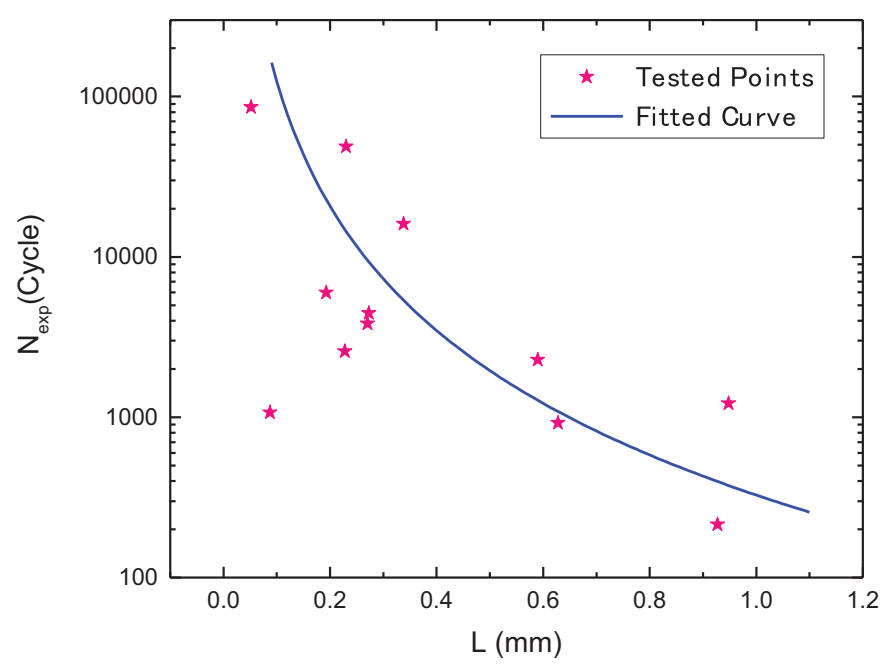

(b)

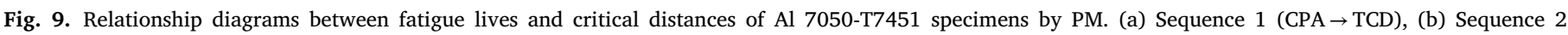
$(\mathrm{TCD} \rightarrow \mathrm{CPA})$.

Table 5

Calculated value of the critical distance (Al 7050-T7451).

\begin{tabular}{lllll}
\hline \multirow{2}{*}{$\begin{array}{l}\text { Coupling } \\
\text { sequence }\end{array}$} & \multicolumn{2}{l}{ Sequence $1(\mathrm{CPA} \rightarrow \mathrm{TCD})$} & \multicolumn{2}{l}{ Sequence $2(\mathrm{TCD} \rightarrow \mathrm{CPA})$} \\
& $\mathrm{PM}$ & $\mathrm{LM}$ & $\mathrm{PM}$ & $\mathrm{LM}$ \\
\hline Critical distance $L(\mathrm{~mm})$ & 0.4990 & 0.7694 & 0.3971 & 0.6441 \\
\hline
\end{tabular}

then fatigue life-critical distance curves in the form of Eq. (7) can be obtained by fitting the data points.

Besides, the critical distance can also be treated as a material constant. Herein, the mean value of critical distance of each specimen is treated as the critical distance constant, their values in various coupling sequence are listed in Table 5.

After determining the value of the critical distance constant or the function between critical distances and fatigue lives, fatigue life of each notched specimen can be evaluated using the eight procedures mentioned above respectively. Among them, computational process of four procedures which regard the critical distance as a material constant are relatively simple. In these procedures, only the stress-strain data in the point of the value of the critical distance constant from the critical point are needed for fatigue strength assessment. However, the procedures which regards the critical distance as a function related to fatigue life are more complicated. Since only the stress-strain state of the test specimen can be extracted at the beginning, neither the life nor the critical distance is known. In addition, note from their relationship expression, the critical distance changes with fatigue lives, thus a complex recursive procedure is required. As depicted in Fig. 11, start from a given initial life value $N_{f 1}$, the value of the critical distance $L_{1}$ can be calculated according to Eq. (7); then the stress-strain state at the point of the value of critical distance $L_{1}$ from the critical point can be extracted, and the damage parameter can be determined to calculate the fatigue life $N_{f 2}$. If $N_{f 1} \neq N_{f 2}$, then assign the value of $N_{f 2}$ to $N_{f 1}$, and continue the recursive procedure; if $N_{f 1}=N_{f 2}$, then stop the recursive procedure, and output the values of the predicted life and the critical distance. 


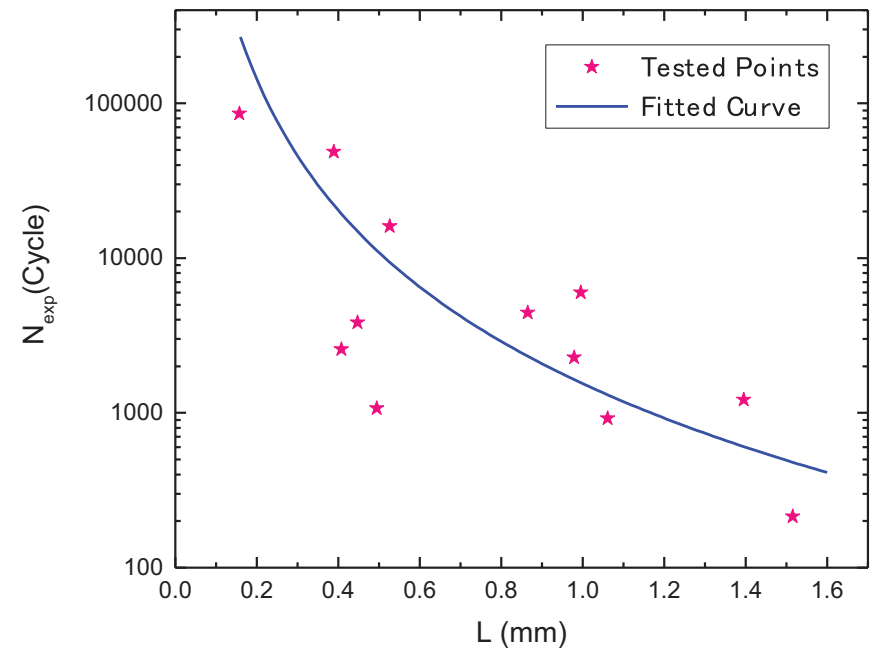

(a)

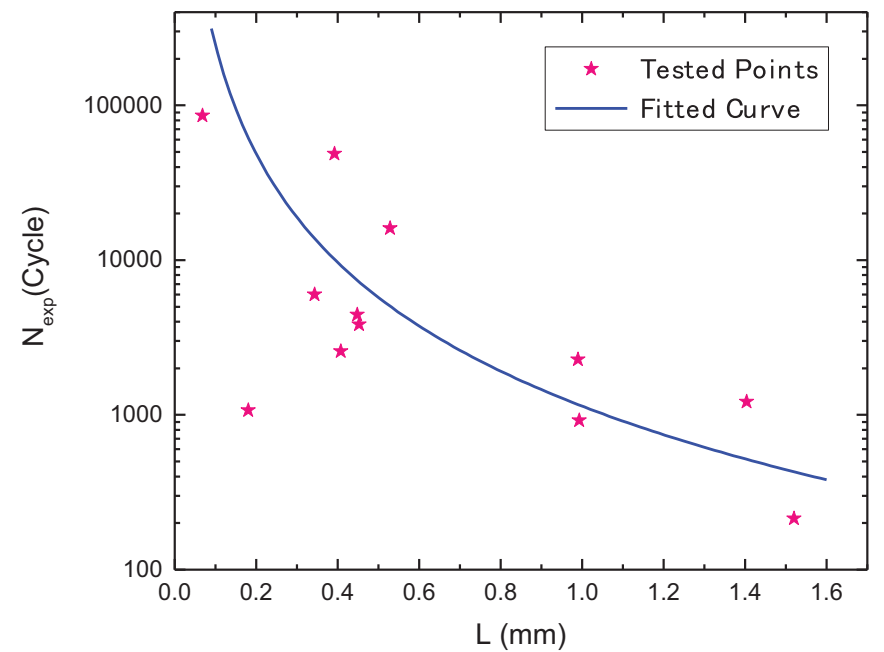

(b)

Fig. 10. Relationship diagrams between fatigue lives and critical distances of Al 7050-T7451 specimens by LM. (a) Sequence 1 (CPA $\rightarrow$ TCD), (b) Sequence 2 $(\mathrm{TCD} \rightarrow \mathrm{CPA}$ ).

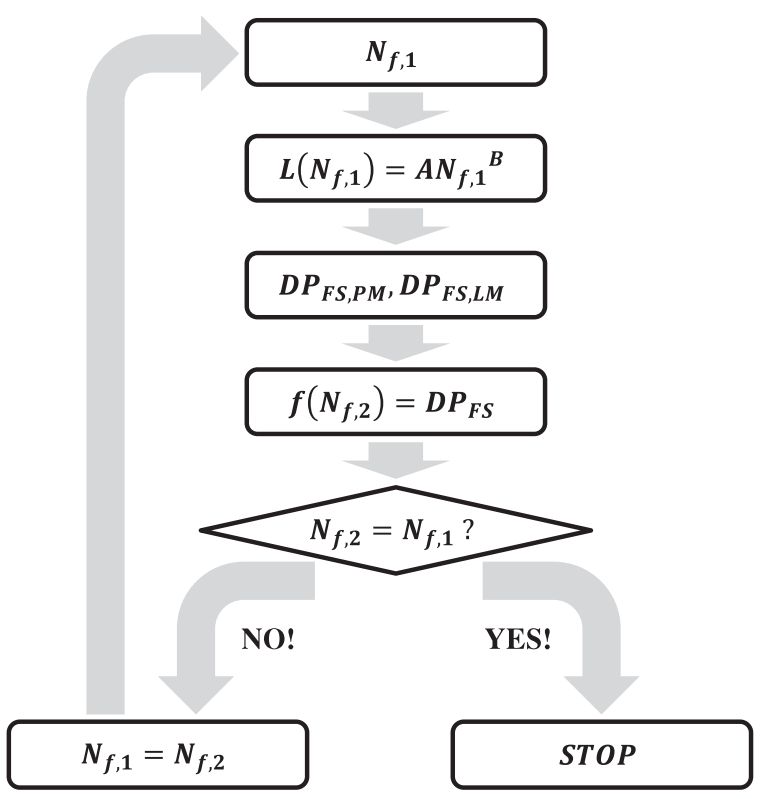

Fig. 11. Flowchart for recursive analysis by coupling the TCD and the FS model.

Comparison between predicted and test lives of the Al 7050-T7451 notched specimens using the abovementioned eight procedures are shown in Fig. 12. Note from the graphs, regardless of the influence of the coupling sequence and the employment of PM or LM in the TCD on the predicting performance, the procedures which regard the critical distance as a function of fatigue life yields better predictions than those treating it as a material constant. In fact, this result can be foreseen from the relationship diagram between testes lives and corresponding critical distances (see Figs. 9 and 10, in which the critical distance obviously varies with fatigue life.

To better compare the model prediction errors between each procedure, an error index is employed to assess the deviation between evaluated and tested results [82]:

$E_{i}=\log \left(N_{f p, i} / N_{f t, i}\right)$
$\bar{E}=\frac{1}{n} \sum_{i=1}^{n}\left|E_{i}\right|$

where $\bar{E}$ denotes the mean absolute deviation, $E_{i}$ represents the absolute deviation for the $i$ th data, $N_{f p, i}$ and $N_{f t, i}$ are the predicted and tested lives for the $i$ th data, respectively, $n$ is the total number of specimens. The average absolute predicted errors of the aforementioned procedures are listed in Table 6, in which the smaller $\bar{E}$ indicates better prediction accuracy.

Moreover, the experimental results of GH4169 alloy are also utilized for model validation, the predicted lives and errors are given in Fig. 13 and Table 7, respectively.

Combining with the results of procedures verification by using experimental data of Al 7050-T7451 and GH4169 notched specimens, the impacts of the abovementioned three research items on the performance of life evaluation are summarized as follows:

(1) Coupling sequence of the CPA and the TCD:

Note from Tables 6 and 7, the procedures using the TCD after using the CPA (Sequence 1) show relatively better predictions than those procedures with Sequence 2.

(2) Employing the PM or the LM in the TCD:

As shown in Tables 6 and 7, when regarding the critical distance as a material constant, the procedures employing the PM present better precision of life predictions than those using the LM; however, when treating the critical distance as a fatigue life related function, for Al 7050-T7451 specimens, there are no obvious difference between procedures using the PM and LM; while for GH4169 specimes, both the PM with Sequence 1 and LM with Sequence 2 provide better predictions than others.

(3) Regarding the critical distance as a material constant or a life related function:

It can be seen from Tables 6 and 7 that the predicting performance of the procedures regarding the critical distance as a fatigue life related function is far superior to the procedures in which the critical distance $L$ is treated as a material constant. Besides, the relationship diagrams (see Figs. 9 and 10) show that the expressions proposed by Susmel and Taylor [67] is well able to describe the relationship between critical distances and fatigue lives.

In summary, the procedure combing the CPA and the TCD with coupling Sequence 1, and regarding the critical distance $L$ as a function 


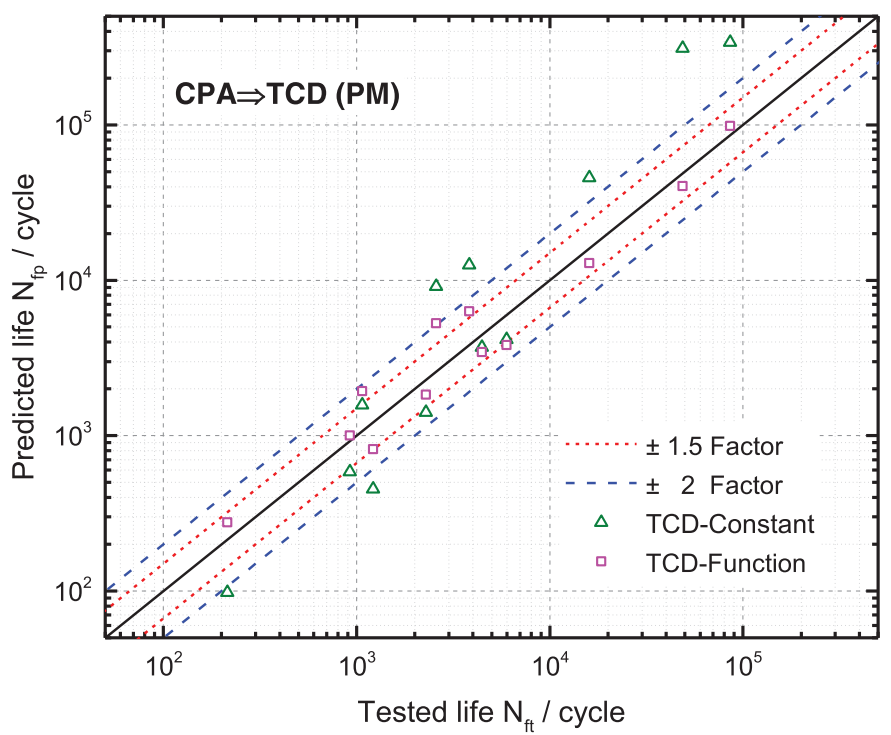

(a)

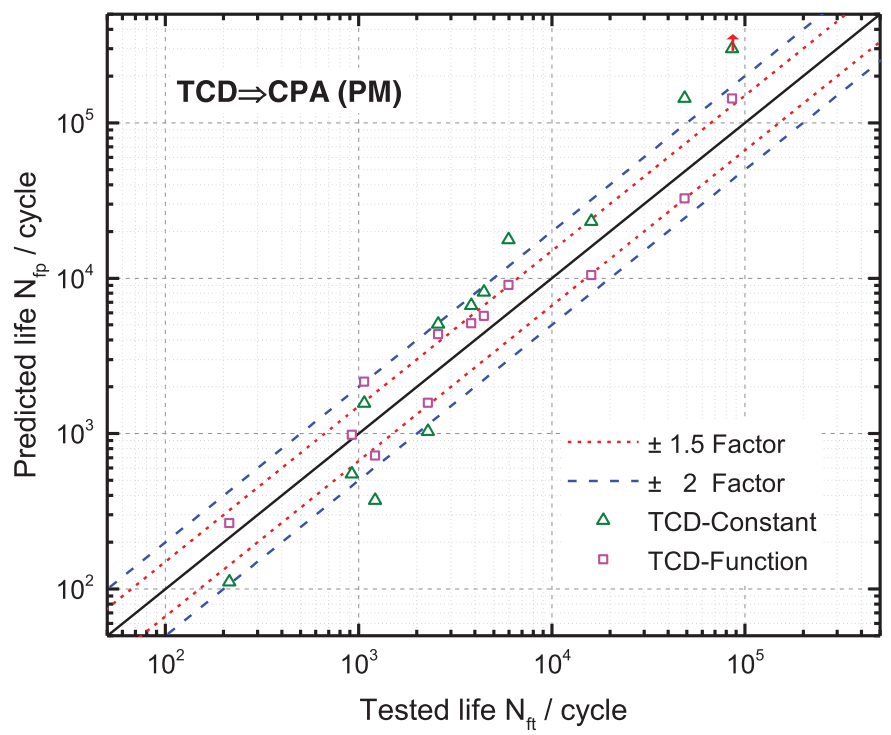

(c)

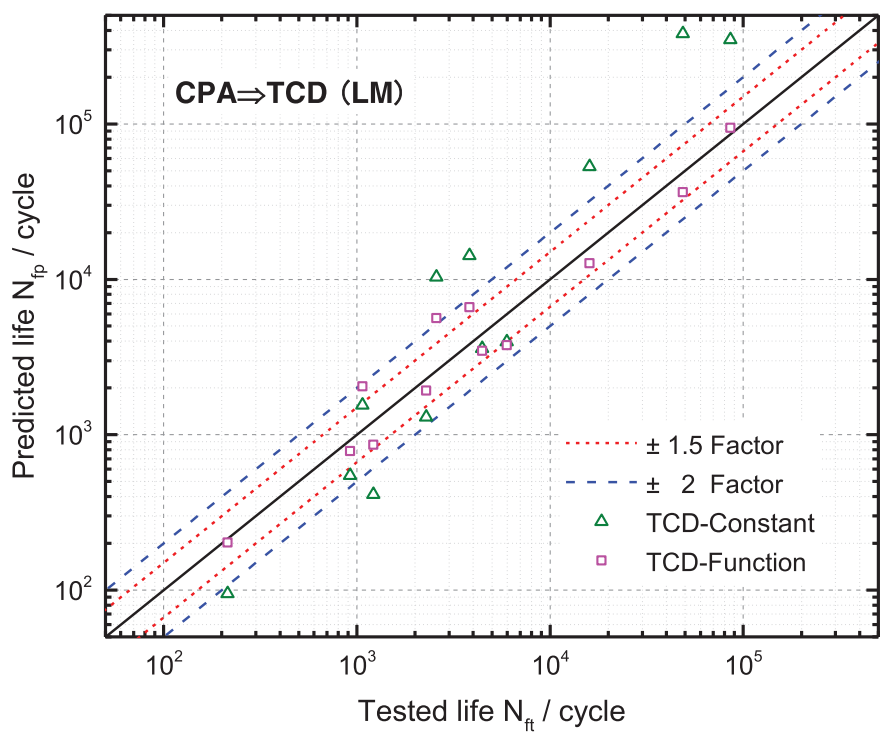

(b)

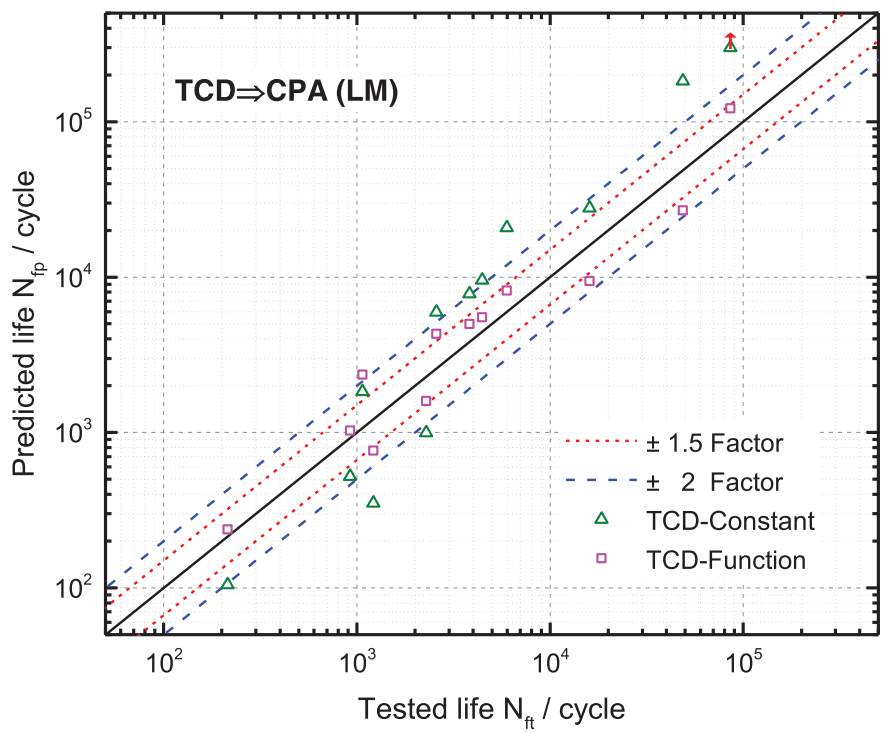

(d)

Fig. 12. Comparison between tested and predicted lives of $\mathrm{Al} 7050-\mathrm{T} 7451$ notched specimens by using

(a) PM of TCD and coupling sequence 1, (b) LM of TCD and coupling sequence 1

(c) PM of TCD and coupling sequence 2, (d) LM of TCD and coupling sequence 2.

Table 6

Average absolute predicted errors of Al 7050-T7451 notched specimens (\%).

\begin{tabular}{llllll}
\hline \multirow{2}{*}{$\begin{array}{l}\text { Coupling } \\
\text { sequence }\end{array}$} & \multicolumn{2}{l}{ Sequence $1(\mathrm{CPA} \rightarrow \mathrm{TCD})$} & \multicolumn{2}{l}{ Sequence $2(\mathrm{TCD} \rightarrow \mathrm{CPA})$} \\
& $\mathrm{PM}$ & $\mathrm{LM}$ & $\mathrm{PM}$ & $\mathrm{LM}$ \\
\hline TCD as a material constant & 37.52 & 41.03 & 39.15 & 45.13 \\
TCD as a life related function & 14.50 & 14.63 & 16.95 & 16.65 \\
\hline
\end{tabular}

Table 7

Average absolute predicted errors of GH4169 notched specimens (\%).

\begin{tabular}{lllll}
\hline \multirow{2}{*}{$\begin{array}{l}\text { Coupling } \\
\text { sequence }\end{array}$} & \multicolumn{2}{l}{ Sequence $1(\mathrm{CPA} \rightarrow \mathrm{TCD})$} & \multicolumn{2}{l}{ Sequence $2(\mathrm{TCD} \rightarrow \mathrm{CPA})$} \\
& PM & LM & PM & LM \\
\hline TCD as a material constant & 14.16 & 18.45 & 27.13 & 28.78 \\
TCD as a life related function & 3.21 & 4.59 & 7.42 & 6.78 \\
\hline
\end{tabular}




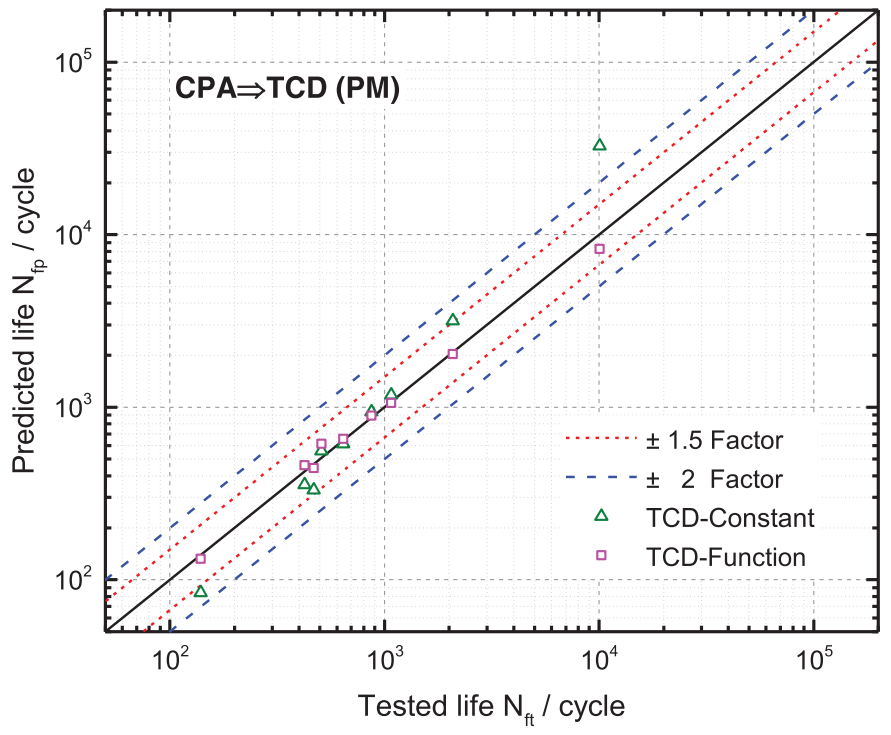

(a)

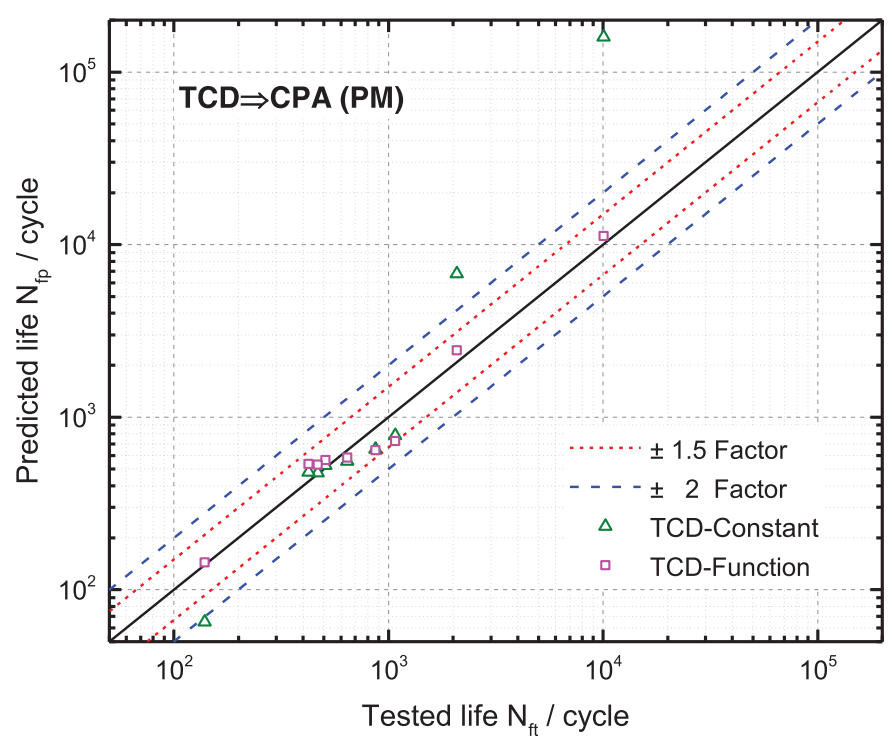

(c)

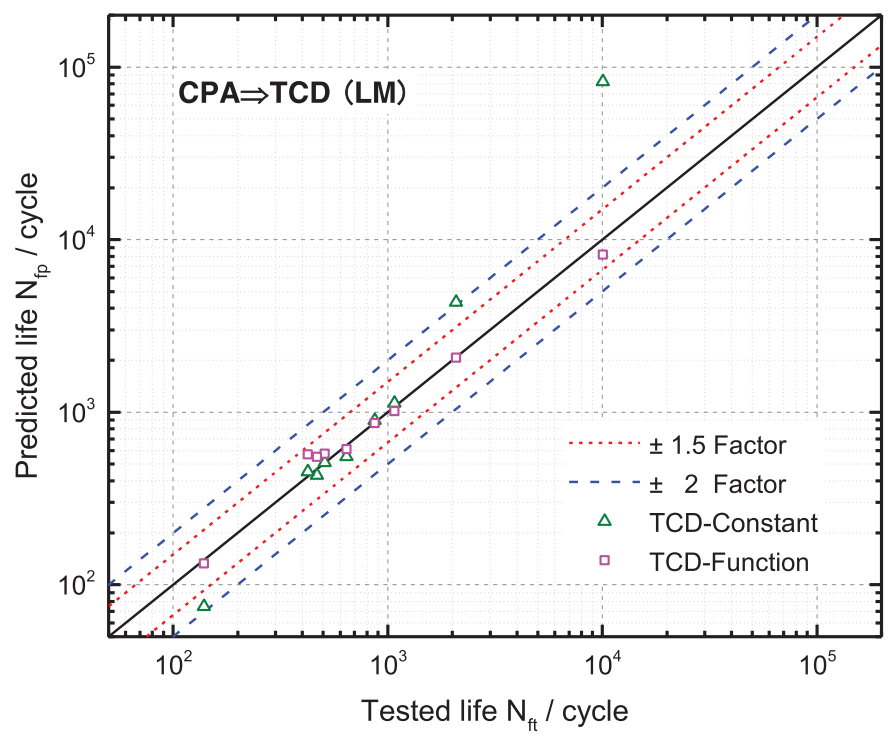

(b)

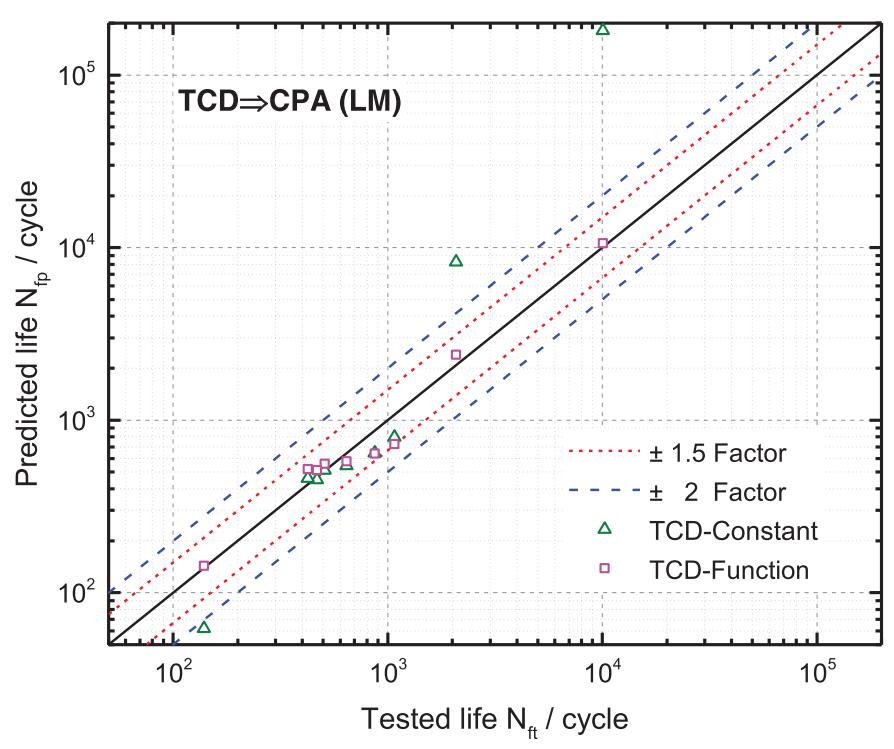

(d)

Fig. 13. Comparison between tested and predicted lives of GH4169 notched specimens by using

(a) PM of TCD and coupling sequence 1, (b) LM of TCD and coupling sequence 1

(c) PM of TCD and coupling sequence 2, (d) LM of TCD and coupling sequence 2 .

related to fatigue life owns the highest accuracy in fatigue life assessment of the two alloys. Noticed from Figs. 12 and 13 that, almost all of predicted points fall within the \pm 2 scatter bands. In this case, the predicted performance by employing the PM and LM in the TCD are very close. Although the PM needs fewer calculating amounts compared with the LM, which seems to save the computational effort. However, in fact, owing to the critical distance $L$ is a function related to fatigue life, thus the value is unknown before determining the fatigue life. Therefore, the procedure of extracting the stress-strain data and calculating the distribution of the damage parameters on the entire path along the direction on which the TCD is applied is inevitable, which occupies most of the calculating resources. Once the relevant information on the entire path is obtained, the difference in the amount of computation when employ- ing the PM and the LM can be ignored. Thus, in general, there is no big difference on the precision of life prediction by employing either the PM or the LM.

\section{Conclusion}

In this work, taking the FS criterion for instance, different coupling sequence of the CPA with the TCD for multiaxial fatigue assessment of notched components is studied. Moreover, the influence of employing the PM and the LM of the TCD on predicting performance as well as the rationality of regarding the critical distance as a material constant or as a fatigue life related function are also investigated. Accordingly, 8 life assessment procedures have been summarized, and experimental 
data of Al 7050-T7451 and GH4169 notched specimens under multiaxial loadings are utilized for model verification and comparison of the eight procedures. The following conclusions can be drawn:

(1) The influence of the coupling sequence of the CPA and the TCD on prediction performance is investigated and discussed, results show that the procedures using the CPA before the TCD own better prediction accuracy than that after the TCD.

(2) A comparison of employing the PM and the LM of the TCD for fatigue life prediction is performed. On one hand, when regarding the critical distance as a material constant, the procedures employing the PM present better precision of prediction than those with the LM; on the other hand, when treating the critical distance as a fatigue life related function, for $\mathrm{Al}$ 7050-T7451 specimens, there are no obvious difference between procedures using the PM and the LM, and for GH4169 specimes, the PM with Sequence 1 as well as the LM with Sequence 2 provide better predictions than others.

(3) The rationality of regarding the critical distance as a material constant or as a function related to fatigue life is investigated. Research indicates that the methods of regarding the critical distance $L$ as a fatigue lifetime related function provides better correlations than others.

(4) By verifying and comparing the eight procedures, the procedures which couple the CPA and the TCD with Sequence 1 and regarding the critical distance as a function related to fatigue life provide better accuracy on fatigue life prediction than others. In these cases, there is no much difference in prediction performance between using the $\mathrm{PM}$ and the LM in the TCD.

\section{Acknowledgement}

The financial support of the National Natural Science Foundation of China (No. 11672070), Sichuan Provincial Key Research and Development Program (No. 2019YFG0348), Science and Technology Program of Guangzhou, China (No. 201904010463), Opening fund of State Key Laboratory of Nonlinear Mechanics, Institute of Mechanics, Chinese Academy of Sciences are acknowledged.

\section{References}

[1] Gates NR, Fatemi A. Multiaxial variable amplitude fatigue life analysis using the critical plane approach, part II: notched specimen experiments and life estimations. Int $J$ Fatigue 2018;106:56-69.

[2] Liao D, Zhu SP, Correia JAFO, De Jesus AMP, Calçada R. Computational framework for multiaxial fatigue life prediction of compressor discs considering notch effects. Eng Fract Mech 2018;202:423-35.

[3] Branco R, et al. Rapid assessment of multiaxial fatigue lifetime in notched components using an averaged strain energy density approach. Int $J$ Fatigue 2019;124:89-98.

[4] Infante-García D, Qian GA, Miguélez H, Giner E. Analysis of the effect of out-of-phase biaxial fatigue loads on crack paths in cruciform specimens using XFEM. Int J Fatigue 2019;123:87-95.

[5] Baumgartner J, Lipp K, Bruder T, Kaufmann H. Design methods for reliable fatigue assessment of PM components. Materwiss Werksttech 2011;42(10):894-903.

[6] Qian GA, Lei WS, Yu ZS, Berto F. Statistical size scaling of breakage strength of irregularly-shaped particles. Theor Appl Fract Mech 2019;102:51-8.

[7] Qian GA, Cao YP, Niffenegger M, Chao YJ, Wu WW. Comparison of constraint analyses with global and local approaches under uniaxial and biaxial loadings. Eur J Mech A/Solids 2018;69:135-46.

[8] Liao D, Zhu SP. Energy field intensity approach for notch fatigue analysis. Int $J$ Fatigue 2019;127:190-202.

[9] Zhang CC, Yao WX. Typical fatigue life analysis approaches for notched components. J Aerosp Power 2013;28(6):1223-30.

[10] Zhu SP, Liu YH, Liu Q, Yu ZY. Strain energy gradient-based LCF life prediction of turbine discs using critical distance concept. Int J Fatigue 2018;113:33-42.

[11] Wu SC, Zhang SQ, Xu ZW, Kang GZ, Cai LX. Cyclic plastic strain based damage tolerance for railway axles in China. Int J Fatigue 2016;93:64-70.

[12] Zhu SP, Liu Q, Peng WW, Zhang XC. Computational-experimental approaches for fatigue reliability assessment of turbine bladed disks. Int $\mathrm{J}$ Mech Sci 2018;142-143:502-17.

[13] Zhu SP, Liu Q, Zhou J, Yu ZY. Fatigue reliability assessment of turbine discs under multi-source uncertainties. Fatigue Fract Eng Mater Struct 2018;41(6):1291-305.

[14] Zhu SP, Liu Q, Lei Q, Wang QY. Probabilistic fatigue life prediction and reliability assessment of a high pressure turbine disc considering load variations. Int J Damage Mech 2018;27(10):1569-88.
[15] Shang DG, Wang DK, Liu M. Multiaxial fatigue life prediction for notched specimens based on the critical plane approach. J Mech Strength 2003;25(2):212-14.

[16] Sun GQ, Shang DG. Prediction of fatigue lifetime under multiaxial cyclic loading using finite element analysis. Mater Des 2010;31(1):126-33.

[17] Liu ET, Shang DG, Chen H, Liu JZ, Tian YJ, Sun GQ. Finite element analysis and life prediction for aluminum notched specimen under multi-axial random strain loading. J Mech Strength 2012;34(4):584-9.

[18] Zhu SP, Foletti S, Beretta S. Probabilistic framework for multiaxial LCF assessment under material variability. Int J Fatigue 2017;103:371-85.

[19] Zhu SP, Yu ZY, Liu O, Ince A. Strain energy-based multiaxial fatigue life prediction under normal/shear stress interaction. Int J Damage Mech 2019;28(5):708-39.

[20] Ince A. Development of computational multiaxial fatigue modelling for notched components. University of Waterloo; 2012.

[21] Ince A, Bang D. Deviatoric neuber method for stress and strain analysis at notches under multiaxial loadings. Int J Fatigue 2017;102:229-40.

[22] Ince A, Glinka G. A critical plane damage parameter for multiaxial fatigue life under proportional and non-proportional loadings. Proceeding of the International Conference on Fatigue Damage of Structural Materials IX; 2012.

[23] Ince A, Glinka G. Innovative computational modeling of multiaxial fatigue analysis for notched components. Int J Fatigue 2016;82:134-45.

[24] Tao ZQ, Shang DG, Sun YJ. New pseudo stress correction method for estimating local strains at notch under multiaxial cyclic loading. Int J Fatigue 2017;103:280-93.

[25] Tao ZQ, Shang DG, Sun YJ, Liu XD, Chen H, Li ZG. Multiaxial notch fatigue life prediction based on pseudo stress correction and finite element analysis under variable amplitude loading. Fatigue Fract Eng Mater Struct 2018;41(8):1674-90.

[26] Susmel L, Taylor D. A critical distance/plane method to estimate finite life of notched components under variable amplitude uniaxial/multiaxial fatigue loading. Int $J \mathrm{Fa}$ tigue 2012;38:7-24.

[27] Wu ZR. Research on multi-axial fatigue life prediction method for titanium alloy. Nanjing university of aeronautics and astronautics; 2014.

[28] Liu XY, Su TX, Zhang Y, Yuan MN. A multiaxial high-cycle fatigue life evaluation model for notched structural components. Int J Fatigue 2015;80:443-8.

[29] Gates NR, Fatemi A. Multiaxial variable amplitude fatigue life analysis including notch effects. Int J Fatigue 2016;91:337-51.

[30] Gates NR, Fatemi A. Notched fatigue behavior and stress analysis under multiaxial states of stress. Int J Fatigue 2014;67:2-14.

[31] Berto F, Lazzarin P, Yates JR. Multiaxial fatigue of V-notched steel specimens: a non-conventional application of the local energy method. Fatigue Fract Eng Mater Struct 2011;34(11):921-43.

[32] Berto F, Lazzarin P, Tovo R. Multiaxial fatigue strength of severely notched cast iron specimens. Int J Fatigue 2014;67:15-27.

[33] Razavi SMJ, Peron M, Torgersen J, Berto F, Welo T. 40CrMoV13. 9 notched specimens under multiaxial fatigue: an overview of recent results. Frat ed Integrità Strutt 2017;11(41):440-6.

[34] Branco R, Prates PA, Costa JD, Berto F, Kotousov A. New methodology of fatigue life evaluation for multiaxially loaded notched components based on two uniaxial strain-controlled tests. Int J Fatigue 2018;111:308-20.

[35] Meneghetti G, Campagnolo A, Berto F, Tanaka K. Notched ti-6al-4 V titanium bars under multiaxial fatigue: synthesis of crack initiation life based on the averaged strain energy density. Theor Appl Fract Mech 2018;96:509-33.

[36] Ye DY, Hertel O, Vormwald M. A unified expression of elastic-plastic notch stress-strain calculation in bodies subjected to multiaxial cyclic loading. Int J Solids Struct 2008;45(24):6177-89.

[37] Meggiolaro MA, de Castro JTP, Martha LF, Marques LFN. On the estimation of multiaxial elastoplastic notch stresses and strains under in-phase proportional loadings. Int J Fatigue 2017;100:549-62.

[38] Liu N, Xiao J, Cui XD, Liu P, Lua J. A continuum damage mechanics (CDM) modeling approach for prediction of fatigue failure of metallic bolted joints. Proceeding of the AIAA Scitech 2019 Forum; 2019.

[39] Hassanifard S, Mohtadi-Bonab MA, Jabbari GH. Investigation of fatigue crack propagation in spot-welded joints based on fracture mechanics approach. J Mater Eng Perform 2013;22(1):245-50.

[40] Mohtadi-Bonab MA, Eskandari M, Ghaednia H, Das S. Effect of microstructural parameters on fatigue crack propagation in an API X65 pipeline steel. J Mater Eng Perform 2016;25(11):4933-40.

[41] Luo P, Yao WX, Li P. A notch critical plane approach of multiaxial fatigue life prediction for metallic notched specimens. Fatigue Fract Eng Mater Struct 2019;42(4):854-70.

[42] Zhu SP, Yu ZY, Correia JAFO, De Jesus AMP, Berto F. Evaluation and comparison of critical plane criteria for multiaxial fatigue analysis of ductile and brittle materials. Int $J$ Fatigue 2018;112:279-88.

[43] Ince A, Glinka G. A generalized fatigue damage parameter for multiaxial fatigue life prediction under proportional and non-proportional loadings. Int $J$ Fatigue 2014;62(2):34-41.

[44] Xu S, Zhu SP, Hao YZ, Liao D, Qian GA. A new critical plane-energy model for multiaxial fatigue life prediction of turbine disc alloys. Eng Fail Anal 2018;93:55-63.

[45] Xu S, Zhu SP, Hao YZ, Liao D. Critical plane-based multiaxial fatigue life prediction of turbine disk alloys by refining normal stress sensitivity. $J$ Strain Anal Eng Des 2018;53(8):719-29.

[46] Yu ZY, Zhu SP, Liu Q, Liu YH. A new energy-critical plane damage parameter for multiaxial fatigue life prediction of turbine blades. Materials (Basel) 2017;10(5):513-30.

[47] Liu JH, Zhang Z, Li B, Lang SS. Multiaxial fatigue life prediction of GH4169 alloy based on the critical plane method. Metals (Basel) 2019;9(2):255-64.

[48] Wu ZR, Li X, Fang L, Song YD. Multiaxial fatigue life prediction based on nonlinear continuum damage mechanics and critical plane method. J Mater Eng Perform 2018;27(6):3144-52. 
[49] Socie DF, Marquis GB. Multiaxial fatigue. Warrendale: Society of Automotive Engineers, Inc.; 2000.

[50] Wang YY, Susmel L. The modified Manson-Coffin curve method to estimate fatigue lifetime under complex constant and variable amplitude multiaxial fatigue loading. Int $J$ Fatigue 2016;83:135-49.

[51] Karolczuk A, Macha E. A review of critical plane orientations in multiaxial fatigue failure criteria of metallic materials. Int J Fract 2005;134:267-304.

[52] Yu ZY, Zhu SP, Liu Q, Liu YH. Multiaxial fatigue damage parameter and life prediction without any additional material constants. Materials (Basel) 2017;10(8):923-37.

[53] Yu ZY. Contact stress analysis and life prediction of blade-disk fir-tree attachment. University of Electronic Science and Technology of China; 2018.

[54] Wu ZR, Hu XT, Song YD. Multiaxial fatigue life prediction for titanium alloy TC4 under proportional and nonproportional loading. Int J Fatigue 2014;59:170-5.

[55] Fatemi A, Socie DF. A critical plane approach to multiaxial fatigue damage including out-phase loading. Fatigue Fract Eng Mater Struct 1988;11(3):149-65.

[56] Brown MW, Miller KJ. A theory for fatigue failure under multiaxial stress-strain conditions. Proc Inst Mech Eng 1973;187(1):745-55.

[57] Smith KN, Watson P, Topper TH. A stress-strain function for the fatigue of metals. $J$ Mater 1970;5:767-78.

[58] Susmel L. The theory of critical distances: a review of its applications in fatigue. Eng Fract Mech 2008;75(7):1706-24.

[59] Wang RQ, Liu H, Hu DY, Li D, Mao J. Evaluation of notch size effect on LCF life of TA19 specimens based on the stress gradient modified critical distance method. Fatigue Fract Eng Mater Struct 2018;41(8):1794-809.

[60] Neuber H. Theory of notch stresses: principles for exact stress calculation. Ann Arbor: Edwards Brothers. Inc.; 1946.

[61] Neuber H. Theory of stress concentration for shear-strained prismatical bodies with arbitrary nonlinear stress-strain law. J Appl Mech 1961;28(4):544-50.

[62] Peterson RE. Notch sensitivity. Metal fatigue. New York: McGraw-Hill; 1959.

[63] Taylor D. Geometrical effects in fatigue: a unifying theoretical model. Int J Fatigue 1999;21(5):413-20.

[64] Bellett D, Taylor D, Marco S, Mazzeo E, Guillois J, Pircher T. The fatigue behaviour of three-dimensional stress concentrations. Int J Fatigue 2005;27(3):207-21.

[65] Taylor D. The theory of critical distances: a new perspective in fracture mechanics. Oxford: Elsevier; 2010

[66] Susmel L, Taylor D. A novel formulation of the theory of critical distances to estimate lifetime of notched components in the medium-cycle fatigue regime. Fatigue Fract Eng Mater Struct 2007;30(7):567-81.

[67] Susmel L, Taylor D. An elasto-plastic reformulation of the theory of critical distances to estimate lifetime of notched components failing in the low/medium-cycle fatigue regime. J Eng Mater Technol 2010;132(2):0210021-8.
[68] Yang XG, Wang JK, Liu JL. High temperature LCF life prediction of notched DS Ni-based superalloy using critical distance concept. Int $J$ Fatigue 2011;33(11):1470-6.

[69] Huang J, Yang XG, Shi DQ, Wang JK, Hu XA. Low cycle fatigue life prediction of notched DZ125 component based on combined critical distance-critical plane approach. J Mech Eng 2013;49(22):109-15.

[70] Castro FC, Araújo JA, Zouain N. On the application of multiaxial high-cycle fatigue criteria using the theory of critical distances. Eng Fract Mech 2009;76(4):512-24.

[71] Susmel L, Taylor D. Can the conventional high-cycle multiaxial fatigue criteria be re-interpreted in terms of the theory of critical distances? Struct Durab Heal Monit 2006;2(2):91-108.

[72] Leidermark D, Moverare J, Simonsson K, Sjöström S. A combined critical plane and critical distance approach for predicting fatigue crack initiation in notched single-crystal superalloy components. Int J Fatigue 2011;33(10):1351-9.

[73] Akama M, Ma H, Doi H, Tsujie M. Fatigue crack initiation life prediction of rails using theory of critical distance and critical plane approach. J Comput Sci Technol 2012;6(2):54-69.

[74] Jiang YY, Sehitoglu H. A model for rolling contact failure. Wear 1999.

[75] Chen XM, et al. Microstructural evolution of a nickel-based superalloy during hot deformation. Mater Des 2015;77:41-9.

[76] Lin YC, Wen DX, Huang YC, Chen XM, Chen XW. A unified physically based constitutive model for describing strain hardening effect and dynamic recovery behavior of a Ni-based superalloy. J Mater Res 2015;30(24):3784-94.

[77] Lin YC, Deng J, Jiang YQ, Wen DX, Liu G. Effects of initial $\delta$ phase on hot tensile deformation behaviors and fracture characteristics of a typical Ni-based superalloy. Mater Sci Eng A 2014;598:251-62.

[78] Mäde L, Schmitz S, Gottschalk H, Beck T. Combined notch and size effect modeling in a local probabilistic approach for LCF. Comput Mater Sci 2018;142:377-88.

[79] Ai Y, Zhu SP, Liao D, Correia JAFO, De Jesus AMP, Keshtegar B. Probabilistic modelling of notch fatigue and size effect of components using highly stressed volume approach. Int J Fatigue 2019;127:110-19.

[80] Ai Y, et al. Probabilistic modeling of fatigue life distribution and size effect of components with random defects. Int J Fatigue 2019;126:165-73.

[81] Zhu SP, Foletti S, Beretta S. Evaluation of size effect on strain-controlled fatigue behavior of a quench and tempered rotor steel: experimental and numerical study. Mater Sci Eng A 2018;735:423-35.

[82] Wang RQ, Li D, Hu DY, Meng FC, Liu H, Ma QH. A combined critical distance and highly-stressed-volume model to evaluate the statistical size effect of the stress concentrator on low cycle fatigue of TA19 plate. Int J Fatigue 2016;95:8-17. 